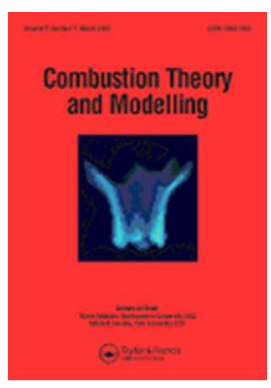

\title{
Cenosphere formation from heavy fuel oil: A numerical analysis accounting for the balance between porous shells and internal pressure
}

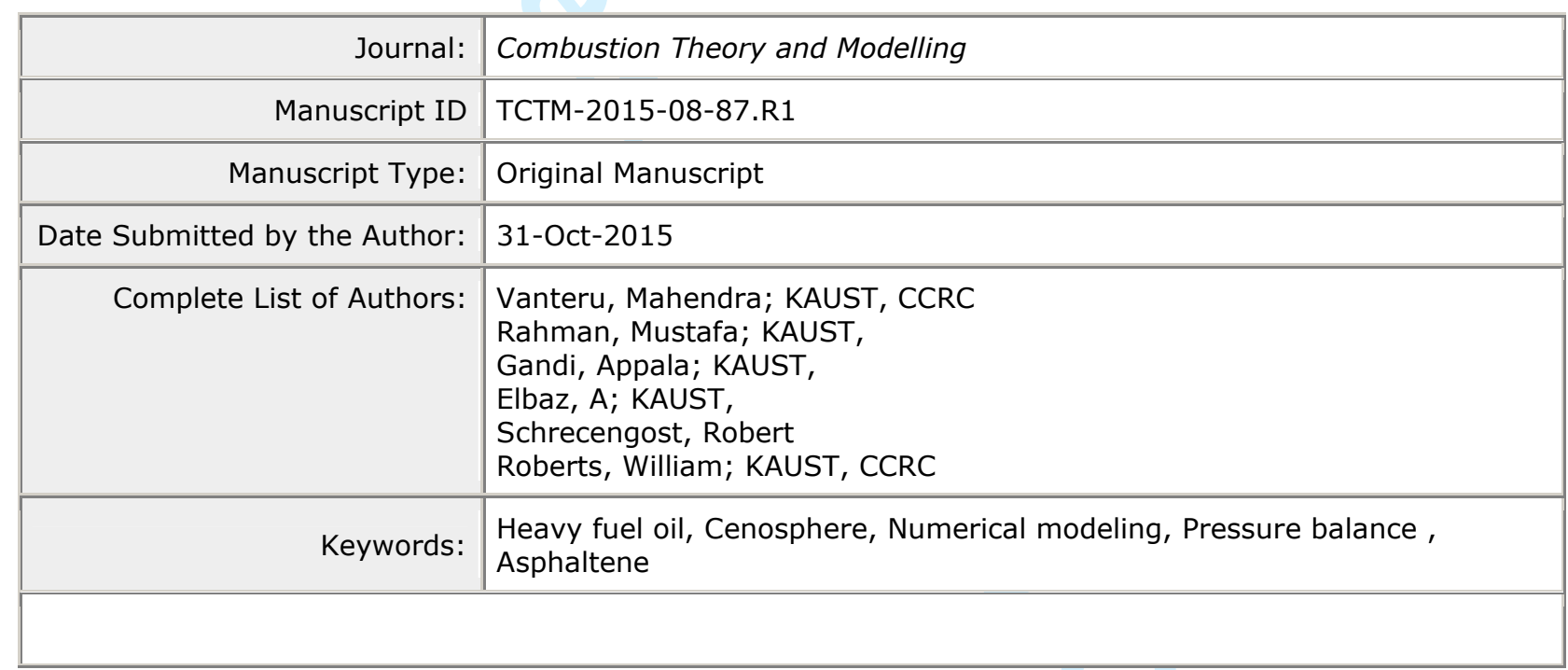

\section{SCHOLARONE \\ Manuscripts}




\title{
Cenosphere formation from heavy fuel oil: A numerical analysis accounting for the balance between porous shells and internal pressure
}

\author{
V. Mahendra Reddy ${ }^{1}$, Mustafa M. Rahman', Appala N. Gandi ${ }^{3}$, A. M. Elbaz ${ }^{1,4}$, \\ Robert A. Schrecengost ${ }^{5}$, William L. Roberts ${ }^{1^{*}}$ \\ ${ }^{1}$ Clean Combustion Research Center, King Abdullah University of Science and Technology, \\ Thuwal, Saudi Arabia \\ ${ }^{2}$ Mechanical Engineering Program, PSE Division, King Abdullah University of Science and \\ Technology, Thuwal, Saudi Arabia \\ ${ }^{3}$ Computational Physics \& Materials Science, PSE Division, King Abdullah University of \\ Science and Technology, Thuwal, Saudi Arabia \\ ${ }^{4}$ Mechanical power department, Faculty of Engineering Materia, Helwan University, Cairo, \\ Egypt \\ ${ }^{5}$ Alstom Power Inc. Windsor CT, USA
}

\begin{abstract}
:
Heavy fuel oil (HFO) as a fuel in industrial and power generation plants ensures the availability of energy at economy. Coke and cenosphere emissions from HFO combustion need to be controlled by particulate control equipment such as electrostatic precipitators, and collection effectiveness is impacted by the properties of these particulates. The cenosphere formation is a function of HFO composition, which varies depending on the source of the HFO. Numerical modeling of the cenosphere formation mechanism presented in this paper is an economical method of characterizing cenosphere formation potential for HFO in comparison to experimental analysis of individual HFO samples, leading to better control and collection.

\footnotetext{
1william.roberts@kaust.edu.sa; Phone: +966 12 808-4909
} 
In the present work, a novel numerical model is developed for understanding the global cenosphere formation mechanism. The critical diameter of the cenosphere is modeled based on the balance between two pressures developed in an HFO droplet. First is the pressure $\left(\operatorname{Pr}_{p f}\right)$ developed at the interface of liquid surface and inner surface of the accumulated coke due to the flow restriction of volatile components from the interior of the droplet. Second is the pressure due to the outer shell strength $\left(P r_{C}\right)$ gained from van der Walls energy of the coke layers and surface energy. In this present study it is considered that when $\operatorname{Pr}_{C} \geq P r_{p f}$ the outer shell starts to harden. The internal motion in the shell layer ceases and the outer diameter $\left(D_{\text {Sout }}\right)$ of the shell is then fixed.

The entire process of cenosphere formation in this study is analyzed in three phases: regression, shell formation and hardening, and post shell hardening. Variations in pressures during shell formation is analyzed. Shell (cenosphere) dimensions are evaluated at the completion of droplet evaporation. The rate of fuel evaporation, rate of coke formation and coke accumulation are analyzed. The model predicts shell outer diameters of 650,860 and $1040 \mu \mathrm{m}$, and inner diamerers are 360,410 and $430 \mu \mathrm{m}$ respectively, for 700, 900 and $1100 \mu \mathrm{m}$ HFO droplets. The present numerical model is validated with experimental results available from the literature. Total variation between computational and experimental results is in the range of 3 to $7 \%$.

\section{Introduction}

Heavy fuel oil (HFO) produces copious heat energy and is particularly useful in industrial settings and electric power stations [1]. Soot formation of carbonaceous particulates from HFO combustion results in ultrafine particles $(\sim 0.1 \mu \mathrm{m})$ and can cause adverse health effects in 
humans [2, 3]. Apart from health concerns, production of larger carbonaceous particulates known as cenospheres $(50-1000 \mu \mathrm{m})$ also results in increased fouling and corrosion of heat transfer surfaces, which increases equipment maintenance costs and downtime. Formation of cenospheres have been noted primarily in HFO combustion and generally this has been ascribed to the presence of asphaltenes in such fuels $[5,6]$. In general, emissions from HFO combustion systems are gaseous pollutants such as $\mathrm{CO}_{2}, \mathrm{CO}, \mathrm{SO}_{2}, \mathrm{NOx}$, etc., and carbonaceous particulates such as submicron soot and much larger cenospheres. Costly counter measures are required in the combustion process or for installation of air quality control systems to meet emissions standards [4].

When a droplet of HFO enters a combustor, heat causes vaporization of the volatiles, which eventually ignite and burn. A rise in temperature leads to cracking (pyrolysis) reactions and local formation of solids that accumulate on the surface of the droplet. The accumulated particles form a film that is permeable to volatiles, allowing continuous evaporation of the inner liquid. When all the volatiles have evaporated, the flame around the droplet runs out of fuel and dies out. The so-formed remaining hard structure is called a cenosphere [1]. The production of cenospheres has been observed in HFO combustion and has generally been ascribed to the presence of asphaltenes in the fuel [5]. Asphaltenes can be schematically described as aromatic units linked by alkyl chains. They are correspond to the part of the fuel which is soluble in benzene and insoluble in heptane [7]. Asphaltenes are the fraction of the oil that produces the highest amount of coke with activation energies of 94 to $135 \mathrm{~kJ} / \mathrm{mol}$ [6]. When the as-formed cenosphere is heated and subsequently ignites in an oxygen-poor atmosphere, it burns via a heterogeneous surface reaction. The reaction rate is limited by the oxygen supply. Sharp falls in temperature 
and oxygen concentration at the exit of the combustion chamber cause cenosphere combustion to cease, which allows its emission to the atmosphere and produces harmful unburned carbon particulate emissions.

Cenosphere formation has been studied experimentally and numerically. Experimental methods used to study cenosphere formation from HFO include sample collection from boilers, the suspended droplet method, and freely falling droplet techniques. However, the composition of HFO changes depending on the source, and cenosphere formation depends on HFO composition. Experimental methods that do not account for HFO composition can thus have limited value. Numerical modeling, on the other hand, can be useful in the analysis of the formation of cenospheres from a particular HFO. A few numerical studies on cenosphere formation in HFO have previously been conducted. These few studies have considered the direct asphaltene-tocoke reaction $[1,8,9]$ because asphaltene in HFO droplets reacts differently in different temperature zones in the droplet and produces various products, including gas, coke, middle oil and light oil $[10,11]$. The influence of these products on the rate of coke formation has not yet been fully considered.

Antaki [8] described constant-diameter burning in the presence of a continuously thickening, rigid porous shell with a regressing liquid surface. Antaki's model has been called the $\mathrm{d}^{3}-1 \mathrm{aw}$. In addition to violating conservation of mass, Antaki's model suggested that solid particles agglomerate precisely when the liquid component is completely depleted, whereas experimental studies have shown that the shell formed with solid particles is hollow in structure $[1,4,6,9]$. Lee and Law [9] and Moszkowicz et al. [1] developed a numerical model to analyze cenosphere 
formation and to explain the shell formation phenomenon. Lee and Law [9] studied the behavior of a slurry droplet under different gasification regimes. The density of the accumulated solid particles on the surface of the droplet increases with the evaporation of the liquid fuel and sweeps radially inward as the surface of the droplet regresses. As gasification continues, the surface density of the particles grows until it reaches a critical porosity. At this point, the particles are sufficiently packed and they cannot be further compressed. Layer thickening then occurs, until the thickness reaches a critical value. The model postulates that when both the layer porosity and thickness reach their respective critical values, a rigid, porous shell is established and the gasification regime switches to a rigid shell regime.

Moszkowicz et al. [1] assumed that there was a critical shell thickness rather than the constant critical diameter assumed by Lee and Law [9]. As soon as this thickness reaches a critical stage, internal coke deposits contribute to an increase in the diameter of the shell. This phenomenon occurs due to a mechanical equilibrium between the overpressure due to vaporization of the liquid within the shell and the pressure loss due to the flow of vapors through the shell. At this stage, the deformation process is very fast and almost unobservable while the mechanical properties of the shell remain unknown. During the increase in the volume inside the shell, vaporization of the liquid continues and a gas bubble forms at the droplet center.

Lee and Law [9] and Moszkowicz et al. [1] did not propose a shell formation mechanism in their numerical methodologies. Here, a numerical model is developed to clarify the mechanism that leads to cenosphere formation from HFO. The critical diameter of the cenosphere is modeled based on the balance between two pressures. These two pressures are the pressure developed due 
to the flow of evaporated fuel through the porous shell and the pressure on the shell due to the van der Walls energy of the coke layers and the surface energy. Three different sized droplets of 700, 900 and $1100 \mu \mathrm{m}$ are considered in the model. Variations in pressures during shell formation and shell dimensions are analyzed and compared. The rates of fuel evaporation, asphaltene reaction, product formation, coke formation and coke accumulation are also analyzed

Table 1 Fuel properties used in the numerical model and Dryer [12]

in relation to variations in the droplet diameter. The influence of the mass flux and the velocity of the evaporated fuel through the porous shells on the pressures during the shell formation stage are also studied. The present numerical model is validated using Dryer et al.'s experimental results $[4,12]$. The properties of the fuel used in the numerical model presented here and in Dryer et al.'s study are listed in the Table 1.

\section{Asphaltene reaction}

Several studies on the cracking of asphaltenes have been reported in the literature. Moschopedis et al. [13], Hayashitani et al. [14, 15], Phillips et al. [7], and Koseoglu and Phillips [11] have developed popular reaction mechanisms that lead to asphaltene cracking. They correlated the reaction rate constants for each of the reaction mechanisms with an Arrhenius-type expression. In this study, the P2 model of Phillips et al. [10] is used for asphaltene reactions in HFO droplets. This model [10] includes all six pseudo-components: coke, asphaltenes, heavy oils, middle oils, light oils and gases. The reaction model is shown in Fig. 1.

Figure 1 The P2 model of the asphaltene cracking mechanism of Phillips et al. [10] 
The activation energies and the frequency factors for this model are given in Table 2. The kinetic reactions based on the Arrhenius equation at each component step are given in Eq. 1 to Eq. 6. These equations (Eq.1 to Eq. 6) calculate the net mass of each component (light, medium, heavy oil, gas, coke and asphaltene) in the droplet after every time step ( $\partial t)$. During the droplet evaporation, the evaporation of light oil, middle oil and heavy oil are continuous processes along with coke and gas formation from asphaltene.

Table 2 Kinetic parameters of the P2 asphaltene cracking model of Phillips et al. [10]

Rate of light oil formation: $\dot{m}_{L O}=k_{6} m_{M O}-\dot{m}_{L O, \text { evap }}$

Rate of middle oil formation: $\dot{m}_{M O}=k_{5} m_{H F O}-\dot{m}_{M O, e v a p}$

Rate of HFO formation: $\dot{m}_{H F O}=k_{2} m_{A}-k_{4} m_{H F O}-k_{5} m_{H F O}-\dot{m}_{H F O, e v a p}$

Rate of asphaltene reaction: $\dot{m}_{A}=k_{4} m_{H F O}-k_{2} m_{A}-k_{1} m_{A}-k_{3} m_{A}$

Rate of gas formation: $\dot{m}_{g a s}=k_{3} m_{A}$

Rate of coke formation: $\dot{m}_{\text {coke }}=k_{1} m_{A}$

\section{Mathematical Modeling}

With their multicomponent composition, HFO droplets possess individual physical and chemical properties. As a consequence, transient heating of the droplet is considered. The temperature distribution in the radial direction is calculated based on the conduction equation [16-18], Eq. 7. Evaporation, product formation from asphaltene, and coke accumulation on the surface of the droplet are simultaneous processes. The entire process of volatile matter evaporation and shell 
(cenosphere) formation is analyzed in three phases: regression, shell formation and hardening, and after shell hardening is completed. A droplet is heated by convection from the surrounding hot gas. The radial temperature gradient decreases with time. Additional heat transfer to the droplet helps with evaporation at the outer surface.

Radial distribution of temperature in the droplet: $\frac{\partial \mathrm{T}}{\partial \mathrm{t}}=k\left(\frac{\partial^{2} T}{\partial R^{2}}+\frac{2}{R} \frac{\partial \mathrm{T}}{\partial \mathrm{R}}\right)$

\subsection{Phase one: Regression Phase}

In the regression phase, the evaporation of the droplet follows Spalding's evaporation equations for a single fuel drop $[9,18,19]$, equations are shown in Eq. 8 to 11 .

$\frac{\partial m_{l}}{\partial t}=-2 \pi D_{\operatorname{Sin}} \frac{k_{l}}{C_{p_{l}}} \ln \left(1+B_{M}\right)$

$B_{M}=\frac{Y_{F_{S}}}{1-Y_{F_{S}}}$

$\left.Y_{F_{S}}=\left[1+\left(\frac{P}{P_{F_{S}}}-1\right)\right) \frac{M_{A}}{M_{F}}\right]^{-1}$

$P_{F_{S}}=\exp \left[a_{f}-\frac{b_{f}}{T_{S}-43}\right]$

During this phase, the mass of the accumulated coke on the surface of the droplet is low. Layer formation on the surface of the droplet due to coke accumulation is not considered until the total accumulated coke reaches a layer thickness of $10 \mu \mathrm{m}$.

At every time step, the radial temperature distribution and the radius of the droplet are calculated. The droplet is divided into ten annular spherical zones (volumes) of the same thickness $\left(L_{Z}=10 \times d r\right)$. The average temperature $\left(T_{Z, a v g}=\frac{1}{10} \sum T_{Z i}\right)$ and mass of the each spherical layer are calculated. The reaction rate constants $\left(k_{n}\right)$ in the each annular zone $\left(Z_{i}\right)$ is 
calculated according to the zone's average temperature $\left(T_{Z, a v g}\right)$. The asphaltene reaction and rate of formation of its products in the each layer are calculated. The evaporated liquid fuel (HFO, middle oil and light oil) and the gas formed from asphaltene undergo combustion. The initial stage of droplet evaporation and thin coke layer formation during regression period are shown in Fig. $2 \mathrm{a}$ and $\mathrm{b}$.

The shell inner diameter $\left(D_{S i n}\right)$ and outer diameter $\left(D_{\text {Sout }}\right)$ are calculated at each time step by following the Eq. 12 and $13[1,9]$.

Inner diameter of the shell: $D_{\operatorname{Sin}}=\sqrt[3]{\left(\frac{m_{L}}{\rho_{L}}\right) \frac{6}{\pi}}$

Outer diameter of the sphere: $D_{\text {Sout }}=\sqrt[3]{\left(\frac{m_{L}}{\rho_{L}}+\frac{m_{C A}}{\rho_{C A}}\right) \frac{6}{\pi}}$

\subsection{Phase two: Shell formation and hardening}

After the regression phase, the considerable amount of coke accumulated on the surface of the droplet forms a flexible and porous thin layer of coke. The evaporated fuel gases pass through the porous coke layer and develop pressure $\left(P r_{p f}\right)$ at the interface of droplet liquid surface and inner surface of the coke layer. The outer coke shell may expand due to the force due to $P r_{p f}$. The $P r_{p f}$ is calculated by using the momentum equation in spherical porous medium (Eq. 14) $[20,21]$.

$$
\frac{\rho^{f}}{\varepsilon}\left[\frac{\partial u_{i}}{\partial t}+\frac{\partial}{\partial x_{i}}\left(\frac{u_{i} u_{j}}{\varepsilon}\right)\right]=-\frac{1}{\varepsilon} \frac{\partial}{\partial x_{i}}\left(P r_{p f} \varepsilon\right)+\frac{\mu_{e}}{\varepsilon} \frac{\partial^{2} u_{i}}{x_{i}^{2}}-\frac{\mu^{f} u_{i}}{k}-\frac{1.75}{\sqrt{150}} \frac{\rho^{f}}{\sqrt{k}} \frac{|u|}{\varepsilon} u_{i}
$$

At the same time, because of the continuous evaporation of the droplet, the coke shell may also contract due to reduction in the diameter of the liquid droplet. However, the coke shell has its own strength $\left(\mathrm{Pr}_{C}\right)$ due to combined pressures from the compaction pressure between coke particles $\left(P_{M E L}\right)$, surface energy $\left(P_{S E L}\right)$ and van der Waals attraction $\left(P_{v d W}\right)$. 
The self-compaction pressure of the layer [22, 23]

$$
P_{M E L}=\sum_{N=1}^{j} \frac{2 E h^{2}}{\sqrt{3\left(1-v^{2}\right)}\left(R_{L}\right)^{2}}
$$

Here $h$ is the thickness of the each layer, $N$ is the number of layers formed till that time and $R_{L}$ is the Radius of the $n^{\text {th }}$ layer from the center.

Thickness of the coke layer for a period of time: $\frac{\dot{m}_{C A} n d t}{\rho_{C A}}=\frac{\pi}{6}\left[\left(2 h+D_{S i n}\right)^{3}-D_{S i n}{ }^{3}\right]$

$$
R_{L}=\frac{D_{\text {Sin }}}{2}+\sum_{N=1}^{k-1} h_{N}+\frac{h_{N}}{2}
$$

Compaction pressure due to surface energy $[22,23]$

$$
P_{S E L}=\sum_{N=1}^{j} 2 A R_{L}^{-2.83}
$$

Pressure due to van der Waals bonding [22, 23]

$$
P_{v d W}=\sum_{N=1}^{(j-1)} \frac{C_{33}}{6}\left[\left(\frac{\sigma}{\alpha}\right)^{10}-\left(\frac{\sigma}{\alpha}\right)^{4}\right]
$$

Total compaction pressure in the layers

$$
\operatorname{Pr}_{C}=P_{M E L}+P_{S E L}+P_{v d W}
$$

The pressure developed due to the flow of evaporated fuel through the porous shell $\left(P r_{p f}\right)$ and that from the pressure on the shell due to the van der Walls energy of the coke layers and the 
surface energy $\left(P r_{C}\right)$ are compared at each time step. Coke formation is a continuous process and accumulates on the surface of the droplet. Therefore, the mass and total pressure of the coke increase with time. At the same time, the droplet surface area decreases and the mass of the evaporated fuel decreases with time. This may cause the pressure due to flow in the porous shell to be reduced. At one point the $P r_{C}$ starts to dominate the $P r_{p f}$. At that point, shell expansion ceases and the outer surface of the shell becomes hard because there is no motion inside the shell and the heat from the surrounding combustion evaporates any remaining liquid fuel on the shell surface. The outer diameter of the shell (cenosphere) becomes fixed and reaches a critical diameter. The stages of pressure balance and when the shell reaches a critical diameter are shown in Fig. 2c.

Figure 2 The stages of droplet evaporation, shell formation and final cenosphere formation

\subsection{Phase three: Flow through rigid shell}

After hard shell formation, Lee and Law [9] assumed that because the total volume of the droplet is fixed by the rigid shell, the continuous depletion of the liquid due to gasification must create a continuously expanding, vapor-saturated space at the core of slurry inside the shell. This suggestion was idealized by assuming an expanding spherical vapor bubble embedded within the slurry mass of the droplet. Moszkowicz et al. [1] also made the same assumption. In the present analysis it is considered that the liquid in the shell occupies some portion of the shell and the remaining portion may be occupied by gas. Also it is assumed that in the combustor, droplets rotate because of one or a combination of the following reasons: the shear stress developed due to swirl flow or turbulence; rotational motion of the droplet from the nature of the injection; and 
temperature gradients in the vicinity of the droplet. Due to the spin or rotational motion of the droplet, liquid spreads on the inner surface of the shell and keeps the inner surface wet. Hence, it is assumed that the inner surface of the shell is spherical and covered with liquid fuel. The fuel spread in the porous shell evaporates due to the heat transfer from the surrounding combustion. It is assumed that inner surface of the shell is saturated with liquid that is flowing through porous shell. The outer surface of the shell is covered with saturated fuel vapor and hot combustion gases. Continuous evaporation of fuel takes place through this mechanism. Heat transfer and rate of evaporation is modeled with the following equation [24, 25].

$$
a_{l}\left[h_{s-g} \varepsilon\left(T_{g}-T_{S}\right)+h_{l-g} \varepsilon(1-\varepsilon)\left(T_{g}-T_{l}\right)\right]=L \dot{m}_{l S}+Q_{D, \text { Cond }}
$$

Here $h_{s-g}$ is the heat transfer coefficient between solid particles and fluid and $h_{l-g}$ is the heat transfer coefficient between liquid and gas.

$$
\begin{aligned}
& h_{s-g}=\left(2+1.1\left(\frac{\varepsilon \rho_{g} u_{g} d_{c}}{\mu_{f}}\right)^{0.6} \operatorname{Pr}^{1 / 3}\right) \frac{\lambda_{f}}{d_{c}} \\
& h_{l-g}=\left(2+1.1\left(\frac{\varepsilon \rho_{g} u_{g} d_{c}}{\mu_{f}}\right)^{0.6} \operatorname{Pr}^{1 / 3}\right) \frac{\lambda_{f}}{d_{p}} \frac{6(1-\varepsilon)}{d_{c}}
\end{aligned}
$$

The continuous process of evaporation and asphaltene reaction causes coke accumulation on the inner surface of the shell. The volume of the liquid is replaced by gas and finally a cenosphere forms. This phenomenon is shown in Figs. 2d, e and $\mathrm{f}$.

\section{Results and Discussion}

\subsection{Radial temperature distibution and reaction rate constants}

The variations in the reaction constants $\left(\mathrm{k}_{1}\right.$ to $\left.\mathrm{k}_{6}\right)$ at different temperatures are calculated according to Phillips et al.'s [10] kinetic parameters and are shown in Fig. 3a. The direct 
products from the asphltene reaction are coke, gas and HFO. The reaction constant $\left(\mathrm{k}_{6}\right)$ for gas formation from asphltene at any temperature is smaller than the other constants $\left(\mathrm{k}_{1}\right.$ to $\left.\mathrm{k}_{5}\right)$. Hence,

Figure 3 (a) Radial temperature distribution in the droplet; (b) Variation of reaction rate constants

the probability of gas formation from asphaltene is less at any temperature. It is observed that the reaction constants increase with increased temperature. Therefore, the rate of reaction for all conversions will be faster in the outer layers of the droplet. The reaction constants for coke and HFO formation from asphaltene are almost the same at all temperatures. The middle oil formation rate constant is smaller, although it forms from HFO and the HFO concentration is high in the droplet. Therefore, middle oil formation from HFO is considerable. The boiling and evaporation characteristics for middle and light oil are not available in the literature. Hence it is assumed that the boiling and evaporation properties for these both (middle and light oil) are the same as kerosene.

The radial temperature distibution in the droplet is shown in Fig. 3b. The initial temperature of the droplet is $300 \mathrm{~K}$. In the present study it is assumed that the average temperature around the surface of the droplet is constant at $800 \mathrm{~K}$. The gas temperature immediately above the droplet surface is assumed to $1500 \mathrm{~K}$. The radial temperature distribution is analyzed and used before shell formation. At a time of $0.03 \mathrm{~s}$, high temperatures are observed in the outer layers. The inner layers are around room temperature $(300 \mathrm{~K})$. The kinetic reactions for asphaltene conversion take place only in the outer layers. 


\subsection{Pressure balance due to coke accumulation and flow through porous shell}

At the initial stage of droplet evaporation, the thickness of the layer is not considered until a minimum amount of coke is accumulated on the outer surface of the droplet. After a certain amount of coke is accumulated on the surface of the droplet, a thin and porous layer is formed. The evaporated fuel flows through this porous layer. Coke formation and accumulation on the outer surface of the droplet are simultaneous with evaporation. Since the flow is restricted in porous coke, pressure $\left(P r_{p f}\right)$ develops at the interface of the liquid surface and the inner surface of the accumulated coke. The rate of fuel evaporation and the velocity of evaporated fuel passing through the porous shell influence the variation of $P r_{p f}$.

The variation of pressures at the interface of the droplet and coke shell is shown in Fig. 4. During the initial stage of evaporation, the droplet size is bigger and the fuel evaporation mass is high. Therefore, the mass flux of the evaporated fuel through the porous shell is increasing. Hence, the $\left(P r_{p f}\right)$ is increasing as well. At $25-50 \mathrm{~ms}$, as evaporation continues and begins to reduce the droplet size, the mass flux of the evaporated fuel and the velocities are also decreasing. At this point, the $\operatorname{Pr}_{p f}$ also starts to decrease. In bigger droplets, the inner surface area of the shell is high. However, in such droplets, the evaporation rate is also high and the mass flux of the evaporated fuel is less. Therefore, the pressure is lower for bigger droplets. The mass flux variation for the three droplet sizes is shown in the inset of the Fig. 4. The pressure due to shell strength $\left(P r_{C}\right)$ increases with increased thickness of the shell. The material properties and numerical relations for the three cases are the same. The variation in pressure is the same and follows the same trend in the three cases. It is considered that, when $P r_{C} \geq P r_{p f}$ the shell starts 
to harden and the mechanical strength of the shell dominates rather than van der Walls force or the surface tension. Therefore, variation in $\operatorname{Pr}_{C}$ after hard shell formation is not shown in Fig. 4.

Figure 4 Pressure balance for $P r_{p f}$ and $P r_{C}$

\subsection{Variation in shell diameters}

Variations in shell and droplet dimensions are shown in Fig. 5a. When the shell starts to harden

$\left(\operatorname{Pr}_{C} \geq P r_{p f}\right)$, the internal motion (contraction and expansion) in the shell layer ceases and the outer diameter $\left(D_{\text {SOut }}\right)$ of the shell becomes fixed. Until this point, the droplet's diameter is equal to the shell inner diameter. Coke then accumulates on the inner suface of the shell. The continous evaporation of the fuel reduces the droplet size. After the rigid shell begins to form, the rate of reduction in the shell's inner diameter is less than the rate of droplet diameter reduction. Hence, the droplet occupies less volume that then interior of the shell and rests at the bottom of the shell, as shown in Fig 2d. Lee and Law [9] considered that the droplet's diameter is equal to the shell's inner diameter. Lee and Law assumed that the evaporated liquid space is compensated by a bubble at the core of the droplet.

In this study, it is assumed that the droplet shape is distorted from a sperical geometry and that it rests in the shell as the liquid mass. Due to the spinning motion of the shell, the inner suface of the shell is wetted by the liquid drop. The inner surface of the shell is thus considered to be an effective evaporation suface of the liquid in the shell. For 700, 900 and $1100 \mu \mathrm{m}$ droplets, the shell outer diameters are 650, 860 and $1040 \mu \mathrm{m}$, respectively. The shell inner diameters are 360, 410 and $430 \mu \mathrm{m}$, respectively. 
Coke formation rate is a function of the rate of reaction of the droplet. For larger droplets the surface area is high and the temperature of the outer layers are also high, hence the mass of coke formation is high for larger droplets (shown in Fig. 4). The rate of decrease in shell inner diameter increases for larger droplets. The variation in thickness is increased for larger droplets. The variation in shell thickness is shown in Fig. 5b. The thickness of the shell for 700, 900 and $1100 \mu \mathrm{m}$ droplets are $1.15,1.95$ and $3.35 \mu \mathrm{m}$, respectively.

Figure 5 (a) Variation in outer diameter $\left(D_{\text {SOut }}\right)$, inner diameter $\left(D_{S I n}\right)$ of the shell, droplet diameter $\left(D_{I n}\right)$ and (b) Variation in the thickness (h) of the shell in relation to differen droplet diameters

\subsection{Droplet evaporation, gas and coke formation}

The variations in droplet evaporation, gas and coke formation from the asphaltene reaction are shown in Figs. 6 and 7. The surface area of the droplet during the regression period and the inner surface area of the shell (after rigid shell formation) are high for larger droplets. The rate of fuel evaporation is proportional to the surface area of the droplet. The rate of product formation is a function of the rate of asphaltene reaction. Therefore, fuel evaporation rate is higher for bigger droplets. The quantity of asphaltene at high temperatures is higher for larger droplets; hence, the rate of gas and coke fromation from asphaltene is also higher for bigger droplets. The rate of gas

formation at $\mathrm{t}=0.1 \mathrm{~s}$ is $1.6 \times 10^{-11}, 3.9 \times 10^{-11}$ and $7.8 \times 10^{-11} \mathrm{~kg} / \mathrm{s}$ for droplet sizes of 700,900 and $1100 \mu \mathrm{m}$, respectively. All evaporated products of light, middle and heavy oil and gas formed from asphaltene (except coke) are continuously undergoing combustion. The accumulation of 
coke during droplet evaporation is plotted in Fig. 7b. At the $t=0.1 \mathrm{~s}$ instant of time, the fuel evaporation for 700,900 and $1100 \mu \mathrm{m}$ diameter droplets is $0.85 \times 10^{-10}, 1.25 \times 10^{-10}$ and $1.6 \times 10^{-10}$ $\mathrm{kg} / \mathrm{s}$, respectively. The coke accumulation up to $0.1 \mathrm{~s}$ of droplet evaporation is $0.125 \times 10^{-7}$, $0.29 \times 10^{-7}$ and $0.52 \times 10^{-7} \mathrm{~kg}$ for the caes of 700,900 and $1100 \mu \mathrm{m}$, respectively.

Figure 6 Variations in (a) fuel evaporation and (b) gas formation for different droplet diameters

Figure 7 Variations in (a) coke formation and (b) coke accumulation for different droplet diameters

\subsection{Velocity of evaporated fuel through shell}

The evaporated fuel passes through the porous shell. The variations in the velocity of evaporated fuel through the shell for different sized droplets are shown in Fig. 8. At any instant in time, the inner diameter of the shell is higher for larger droplets and vice versa. Hence, the mass flux of evaporated fuel is higher for the case of smaller droplets. Therefore, high velocitiy is observed with small droplets. A drastic decrease in velocity is observed at the end of droplet evaporation. The reason is that the inner shell is considered as a wet surface in this study and evaporation takes place on that surface. At the end of droplet evaporation, the remaining small quanty of fuel reaches to near boiling point and quickly evaporates by spreading on the shell's inner surface. At $0.15 \mathrm{~s}$ for instance, the inner surface areas of the three droples $(700,900$ and $1100 \mu \mathrm{m})$ are $5.67 \times 10^{-7}, 1.28 \times 10^{-6}$ and $2.53 \times 10^{-6} \mathrm{~m}^{2}$, respectively. The outward velocity of the evaporated fuel for three droplets at this particular time is $10.8 \times 10^{-4}, 8.2 \times 10^{-4}$ and $7.1 \times 10^{-4} \mathrm{~m} / \mathrm{s}$, respectively. 
Figure 8 Variation of velocity of evaporated fuel $(\mathrm{m} / \mathrm{s})$ for different droplet diameters

\section{Validation}

The present numerical model is validated with the experimental results of Urban and Dryer [4] and Urban et al. [12]. Properties of the fuel (EPRI 4011) used in Urban et al.'s [12] study are listed in the Table 1. In that study [12], a range of droplets (100 to $700 \mu \mathrm{m})$ of different fuels are tested and the variations in particle (cenosphere) diameter and droplet size are studied. To validate the model's results, droplets of 490, 640 and $690 \mu \mathrm{m}$ of EPRI 4011 fuel are considered and the particle diameter is calculated via the present model. Comparisons between the results from the computation model and experimental observations from Urban et al. [12] are shown in Fig. 9. The cenosphere diameters as given by the model are 340, 505, $670 \mu \mathrm{m}$ for 490, 640 and $690 \mu \mathrm{m}$ droplets, respectively. The experimental observations by Urban et al. [12] measured diameters of 360,545 and $655 \mu \mathrm{m}$ for 490,640 and $690 \mu \mathrm{m}$ droplets, respectively. The total variation between the present computational model and the experimental results of Urban et al. [12] is in the range of 3 to $7 \%$.

Figure 9 (a) Variation of shell dimension of EPRI 4011 of Urban et al., [4, 12] and (b) Comparison of present model with experimental results of Urban et al., [4, 12]

\section{Conclusions}

In the present work, a numerical model is developed to understand the mechanism of cenosphere formation from heavy fuel oil (HFO). Asphaltene reactions in the different temperature zones of 
the droplet are considered according to Phillips et al. [10] and the rate of product formation is analyzed. In the computational model proposed here, the critical diameter of the cenosphere is modeled based on the balance between the two pressures developed during shell formation. Findings include the following:

1. The direct products from the asphltene reaction are coke, gas and HFO. The reaction constant $\left(\mathrm{k}_{6}\right)$ for gas formation from asphaltene is smaller than other constants $\left(\mathrm{k}_{1}\right.$ to $\left.\mathrm{k}_{5}\right)$. Hence, the probability of gas formation from asphaltene is less at any temperature. It is observed that, with increased temperature, the reaction constants are increased. Therefore, the rate of reaction for all conversions will be faster at the outer layers of the droplet. High temperatures are observed in the outer three layers. The kinetic reactions for asphaltene conversion take palce in the outer layers only.

2. Evaporated fuel flows through the porous outer layer. Pressure $\left(P r_{p f}\right)$ develops at the interface of the liquid surface and the inner surface of the accumulated coke due to flow restrictions in porous coke. The inner surface area of the shell is high with bigger droplets. However, the evaporation rate is also high for bigger droplets and the mass flux of the evaporated fuel is less for bigger droplets. The pressure is also low for bigger droplets. The pressure due to shell strength $\left(P r_{C}\right)$ increases with increased thickness of the shell. In this study it is considered that when $P r_{C} \geq P r_{p f}$ the shell starts to harden.

3. When the shell starts to harden $\left(P r_{C} \geq P r_{p f}\right)$ the internal motion in the shell layer ceases and the outer diameter $\left(D_{\text {Sout }}\right)$ is fixed. After rigid shell formation, the rate of inner shell diameter reduction is less than the rate of droplet diameter reduction. Hence, the droplet rests in the shell. The liquid in the droplet spreads on the inner suface of the shell and the wetted 
surface becomes the effective evaporation suface of the liquid. The shell's outer diameters for 700,900 and $1100 \mu \mathrm{m}$ droplets are 650,860 and $1040 \mu \mathrm{m}$, respectively. The inner diameters are 360,410 and $430 \mu \mathrm{m}$, respectively. The rate of coke formtion is high for larger droplets. The rate of decrease in the shell's inner diameter increases with larger droplets. The shell thickness is increased for larger droplets.

4. Since the inner surface area of the shell is high for large droplets, fuel evaporation is high for larger droplets. The rate of coke formation is a function of the mass of liquid fuel evaporation. Coke formation is high for larger droplets. At $t=0.1 \mathrm{~s}$, the fuel evaporation for 700,900 and $1100 \mu \mathrm{m}$ droplets is $0.85 \times 10^{-10}, 1.25 \times 10^{-10}$ and $1.6 \times 10^{-10} \mathrm{~kg} / \mathrm{s}$, respectively. The coke accumulation up to $0.1 \mathrm{~s}$ of droplet evaporation is $0.125 \times 10^{-7}, 0.29 \times 10^{-7}$ and $0.52 \times 10^{-7} \mathrm{~kg}$ for 700,900 and $1100 \mu \mathrm{m}$ droplets, respectively. Since the fuel evaporation rate decreases with time, the coke formation rate also decreases.

5. The inner diameter of the shell is high for larger droplets. The mass flux of the evaporated fuel is thus high with smaller droplets. Therefore, high velocitiy is observed with small droplets. At $0.15 \mathrm{~s}$, the inner surface areas of the shells of the three droplets $(700,900$ and $1100 \mu \mathrm{m})$ are $5.67 \times 10^{-7}, 1.28 \times 10^{-6}$ and $2.53 \times 10^{-6} \mathrm{~m}^{2}$, respectively. The velocity of the evaporated fuel for the three droplets at $0.15 \mathrm{~s}$ is $10.8 \times 10^{-4}, 8.2 \times 10^{-4}$ and $7.1 \times 10^{-4} \mathrm{~m} / \mathrm{s}$, respectively.

Acknowledgements: The authors gratefully acknowledge that this article is based upon research supported by Alstom (Switzerland) Ltd. and Alstom Power Inc. in collaboration with KAUST's Clean Combustion Research Center. 


\section{References}

[1] P. Moszkowicz and L. Witzel, Modelling of very fast pyrolysis of heavy fuel oil droplets, Chem. Eng. Sci. 51 (1996), pp. 4075-4086.

[2] C. Allouis, F. Beretta, and A.D. Alessio, Structure of inorganic and carbonaceous particles emitted from heavy oil combustion, Chemosphere. 51 (2003), pp. 1091-1096.

[3] W.P. Linak, C.A. Miller, and J.O.L. Wendt, Fine particle emissions from residual fuel oil combustion: Characterization and mechanisms of formation, Proc. Combust. Inst. 28 (2000), pp. 2651-2658.

[4] D.L. Urban and F.L. Dryer, New results on coke formation in the combustion of heavy-fuel droplets, Proc. Combust. Inst. 23 (1990), pp. 1437-1443.

[5] A. Ciajolo and R. Barbella, Pyrolysis and oxidation of heavy fuel oils and their fractions in a thermogravimetric apparatus, Fuel. 63 (1984), pp. 657-661.

[6] K.D. Bartle, J.M. Jones, A.R. Lea-Langton, M. Pourkashanian, A.B. Ross, J.S. Thillaimuthu, P.R. Waller, and A. Williams, The combustion of droplets of high-asphaltene heavy oils, Fuel. 103 (2013), pp. 835-842.

[7] N. Bomo, J. Lahaye and G. Prado, Formation of cenospheres during pyrolysis of residual fuel oils, Proc. Combust. Inst. 20 (1985), pp. 903-911.

[8] P. Antaki, Transient Processes in a rigid slurry droplet during liquid vaporization and combustion, Combust. Sci. Technol. 46 (1986), pp. 113-135.

[9] A. Lee, C.K. Law, Gasification and shell characteristics in slurry droplet burning, Combust. Flame. 85 (1991), pp. 77-93.

[10] C.R. Phillips, N.I. Haidar, and Y.C. Poon, Kinetic models for the thermal cracking of Athabasca bitumen -the effect of the sand matrix, Fuel. 64 (1985), pp. 678-691. 
[11] R.O. Koseoglu, and C.R. Phillips, Kinetics of non-catalytic hydrocracking of Athabasca bitumen, Fuel. 66 (1987), pp. 741-748.

[12] D.L. Urban, S.P.C. Hueyt and F.L. Dryer, Evaluation of the coke formation potential of residual fuel oils, Proc. Combust. Inst. 24 (1992), pp. 1357-1364.

[13] S.E. Moschopedis, S. Prakash, and J.G. Speight, Thermal decomposition of asphaltenes, Fuel. 57 ( 1978), pp. 431-434.

[14] Hayashitani, M., Bennion, D.W., Donnelly, J.K. and Moore, R.G., Thermal cracking models for Athabasca oil sands oil. Proc. of Oil Sands of Canada-Venezuela Symposium, CIM Spec. Publ. 17, 233, 1977.

[15] Hayashitani, M., Bennion, D.W., Donnelly, J.K. and Moore, R.G., Thermal cracking models for Athabasca oil sands oil. SPE 7549, $53^{\text {rd }}$ Annual Fall Technical Conference and Exhibition of the SPE, Houston, October 1-3 (1978).

[16] S.S. Sazhin, A.E. Elwardany, P.A. Krutitskii, V. Deprédurand, G. Castanet, F. Lemoine, E.M. Sazhina, and M.R. Heikal, Multi-component droplet heating and evaporation: Numerical simulation versus experimental data, Int. J. Therm. Sci. 50 (2011), pp. 11641180

[17] S.S. Sazhin, M. Al Qubeissi, R. Kolodnytska, A.E. Elwardany, R. Nasiri, and M.R. Heikal, Modelling of biodiesel fuel droplet heating and evaporation, Fuel. 115 (2014), pp. 559572.

[18] S.S. Sazhin, P.A. Krutitskii, I.G. Gusev, and M.R. Heikal, Transient heating of an evaporating droplet, Int. J. Heat Mass Tran. 53 (2010), pp. 2826-2836.

[19] J.S. Chin and A.H. Lefebvre, Steady-State Evaporation Characteristics of Hydrocarbon Fuel Drops. AIAA JOURNAL, VOL. 21, NO. 10, OCTOBER 1983 
[20] S. Ergun, Fluid flow through packed column, Chem. Eng. Prog. 48 (1952), pp. 89-94.

[21] O.C. Zienkiewicz, R.L. Taylor, P. Nithiarasu. The Finite Element Method for Fluid Dynamics (Seventh Edition). 2014; PP 312-.

[22] M. Todt, R.D. Bitsche, M.A. Hartmann, F.D. Fischer, F.G. Rammerstorfer, Growth limit of carbon onions - A continuum mechanical study, Int. J. Solids and Struct. 51 (2014), pp. $706-715$.

[23] M. Todt, F.G. Rammerstorfer, F.D. Fischer, P.H. Mayrhofer, D. Holec, and M.A. Hartmann, Continuum modeling of van der Waals interactions between carbon onion layers, Carbon. 49 (2011), pp. 1620 - 1627.

[24] T.K. Kayal and M. Chakravarty, Modeling of trickle flow liquid fuel combustion in inert porous medium, Int. J. Heat Mass Tran. 49 (2006), pp. 975-983.

[25] P.-X. Jiang and X.-C. Lu, Numerical simulation of fluid flow and convection heat transfer in sintered porous plate channels, Int. J. Heat Mass Tran. 49 (2006), pp. 1685-1695. 


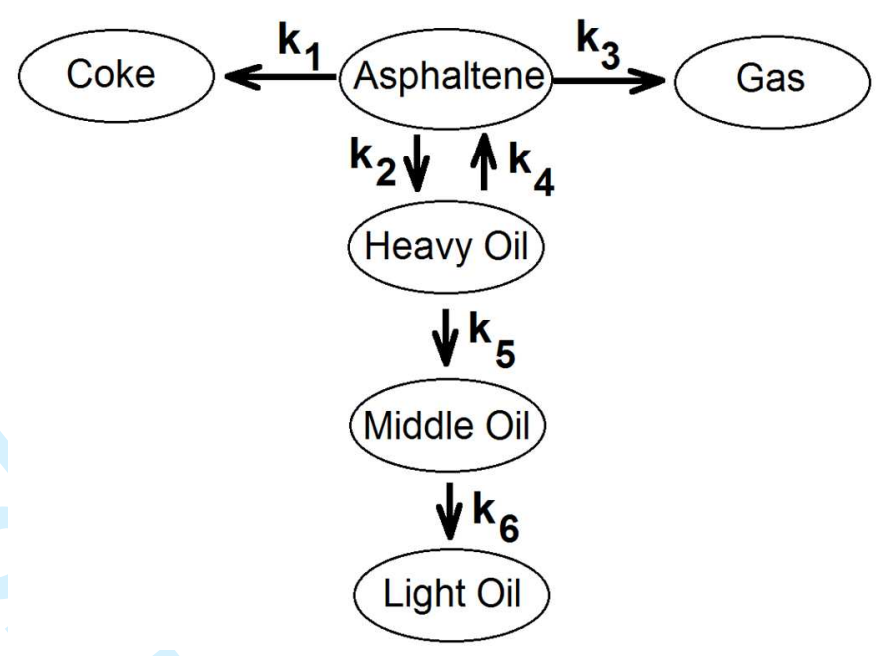

Figure 1 The P2 model of the asphaltene cracking mechanism of Phillips et al. [10] 


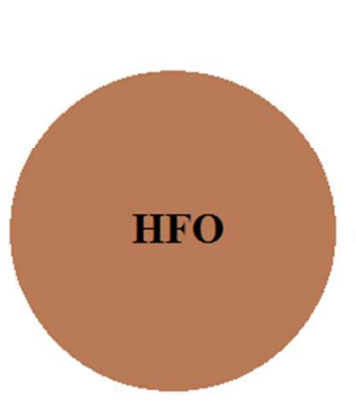

(a)

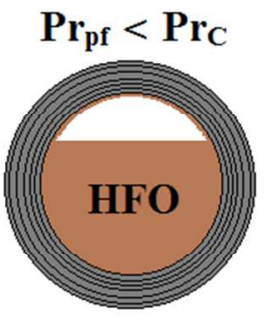

(d)

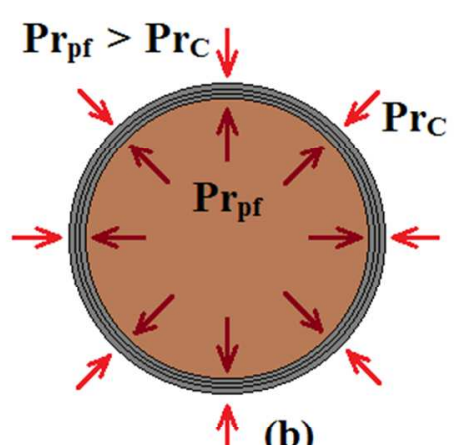

(b)

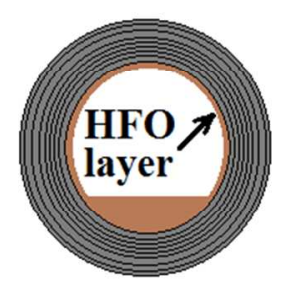

(e)
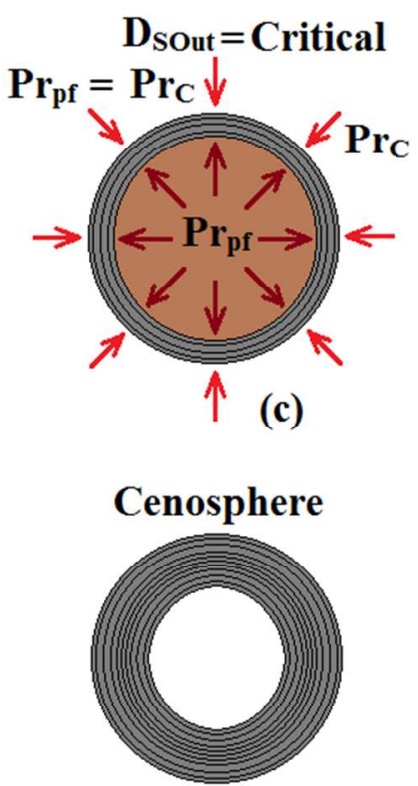

(f)

Figure 2 The stages of droplet evaporation, shell formation and final cenosphere formation 

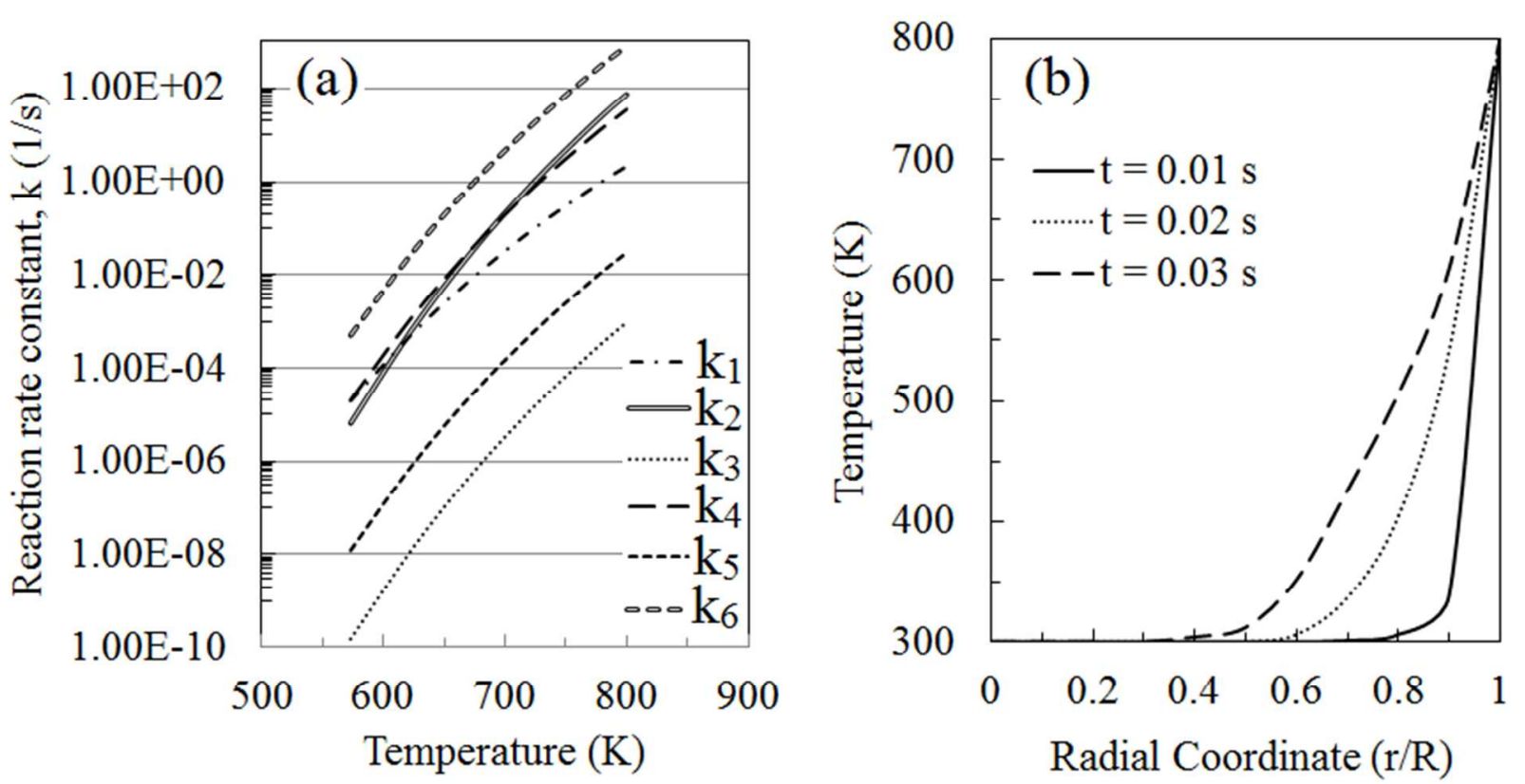

Figure 3 (a) Radial temperature distribution in the droplet; (b) Variation of reaction rate constants 


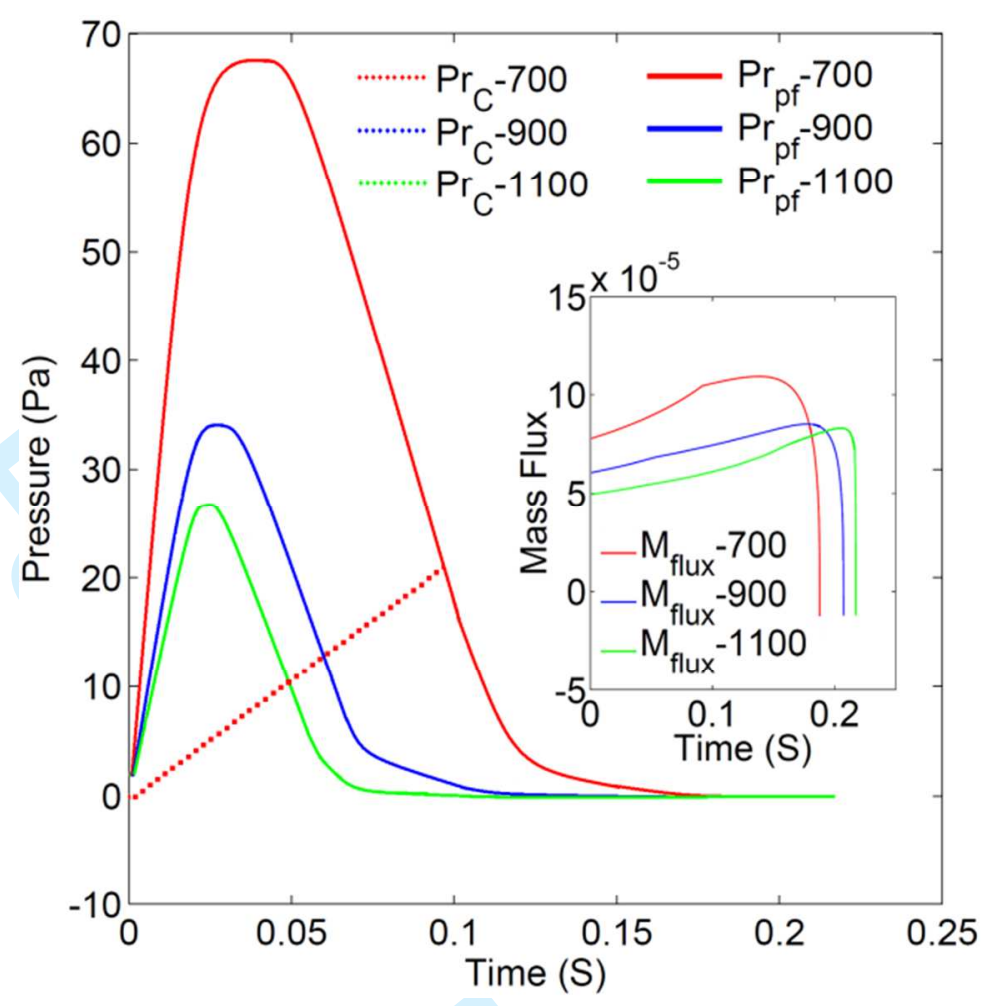

Figure 4 Pressure balance for $P r_{p f}$ and $P r_{C}$ 

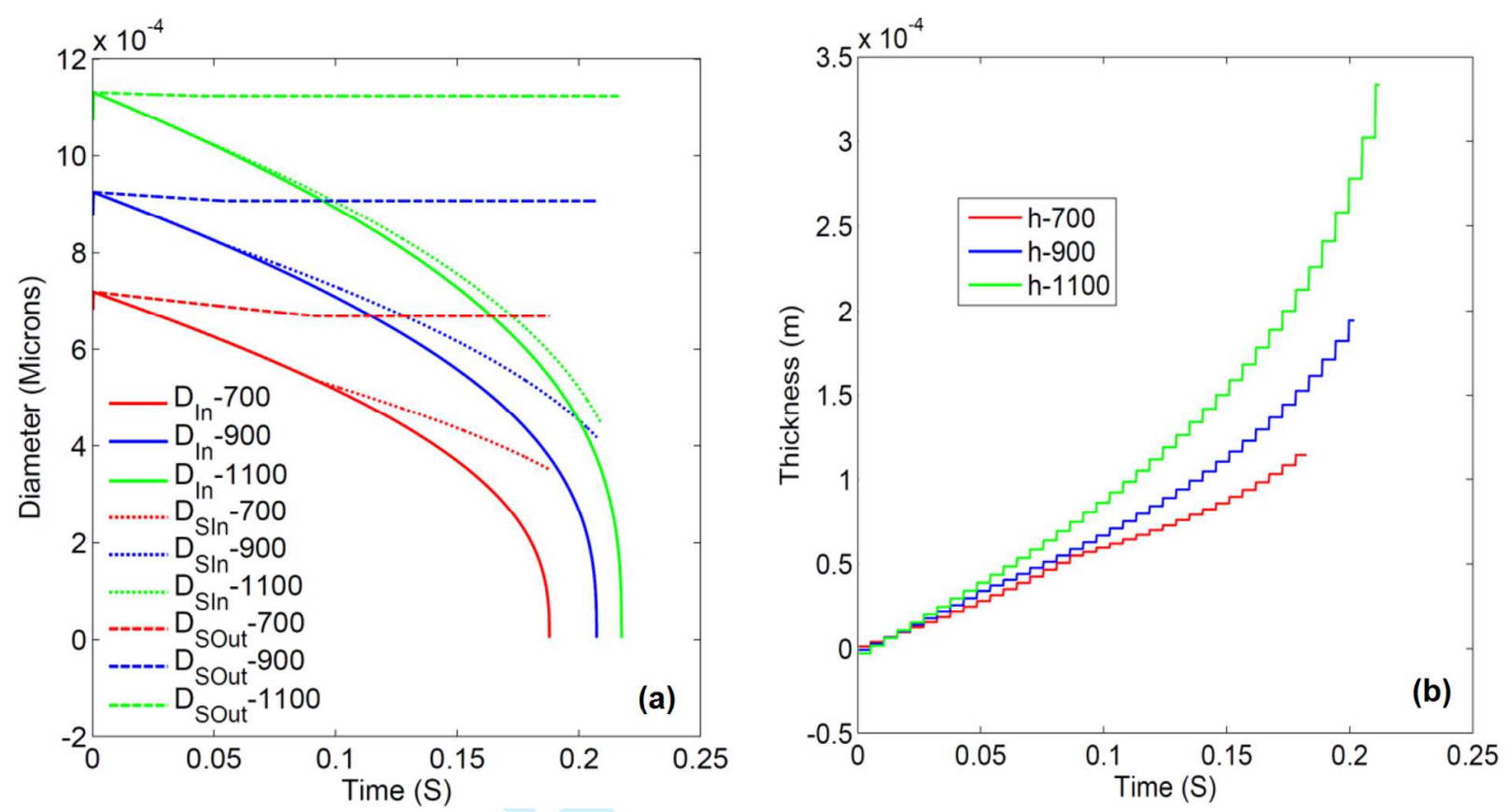

Figure 5 (a) Variation in outer diameter $\left(D_{\text {SOut }}\right)$, inner diameter $\left(D_{\text {SIn }}\right)$ of the shell, droplet diameter $\left(D_{I n}\right)$ and (b) Variation in the thickness (h) of the shell in relation to differen droplet diameters 

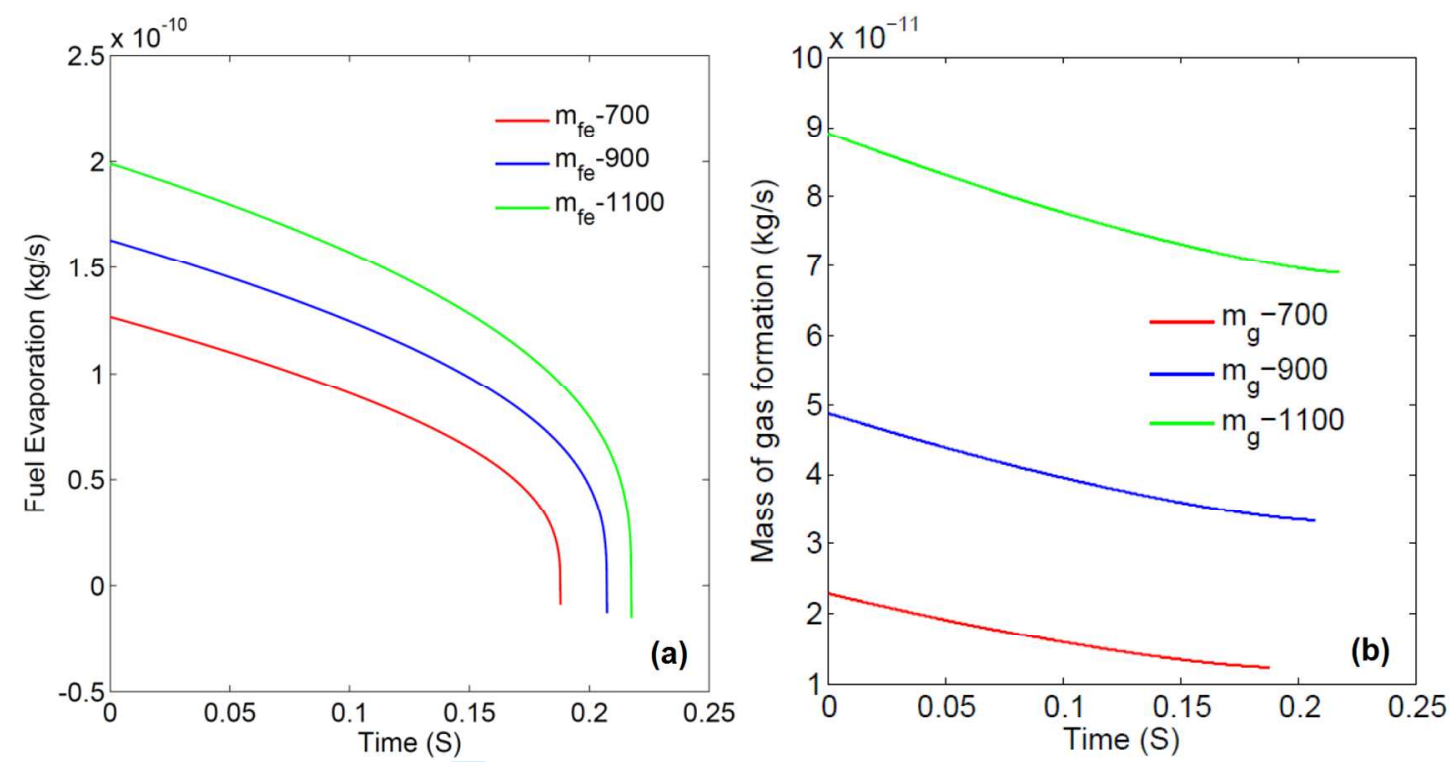

Figure 6 Variations in (a) fuel evaporation and (b) gas formation for different droplet diameters 

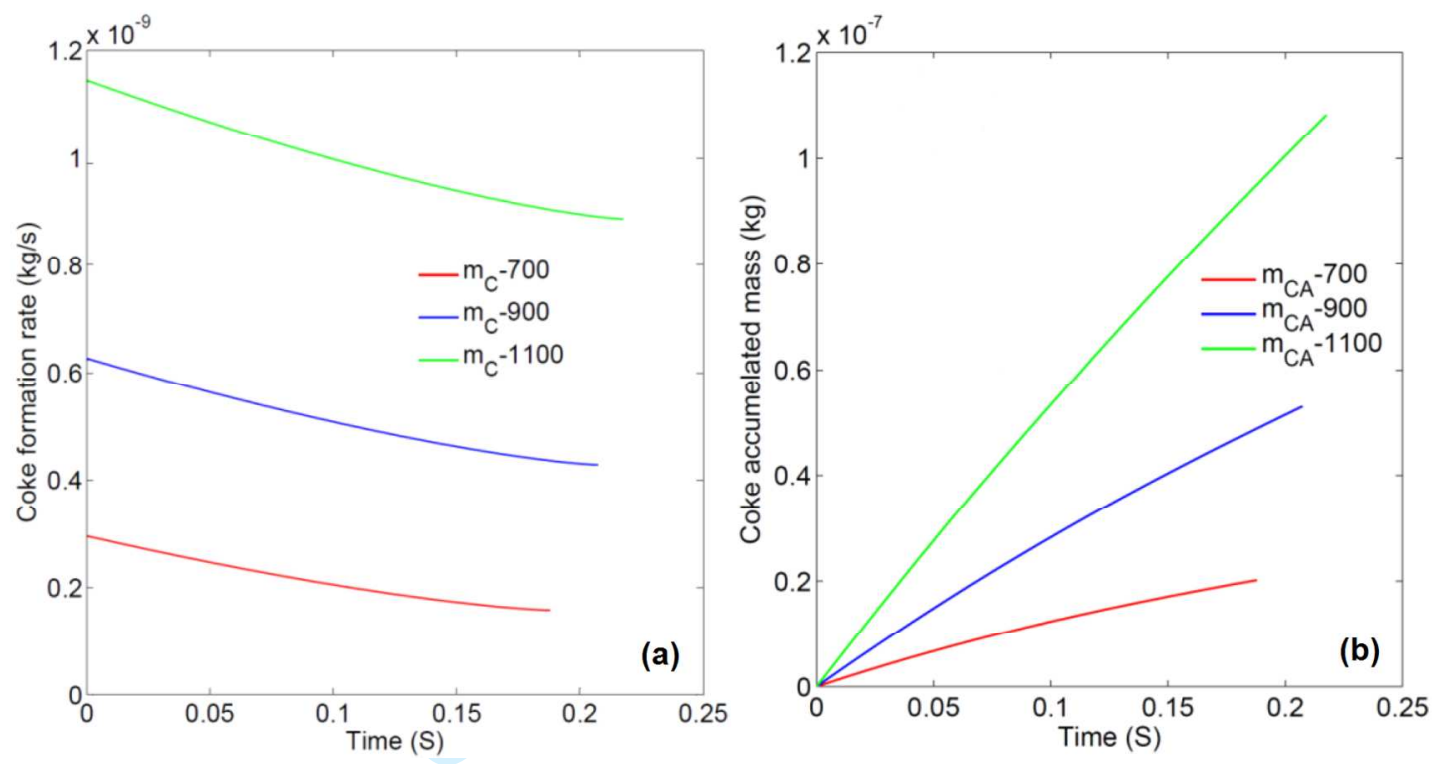

Figure 7 Variations in (a) coke formation and (b) coke accumulation for different droplet diameters 


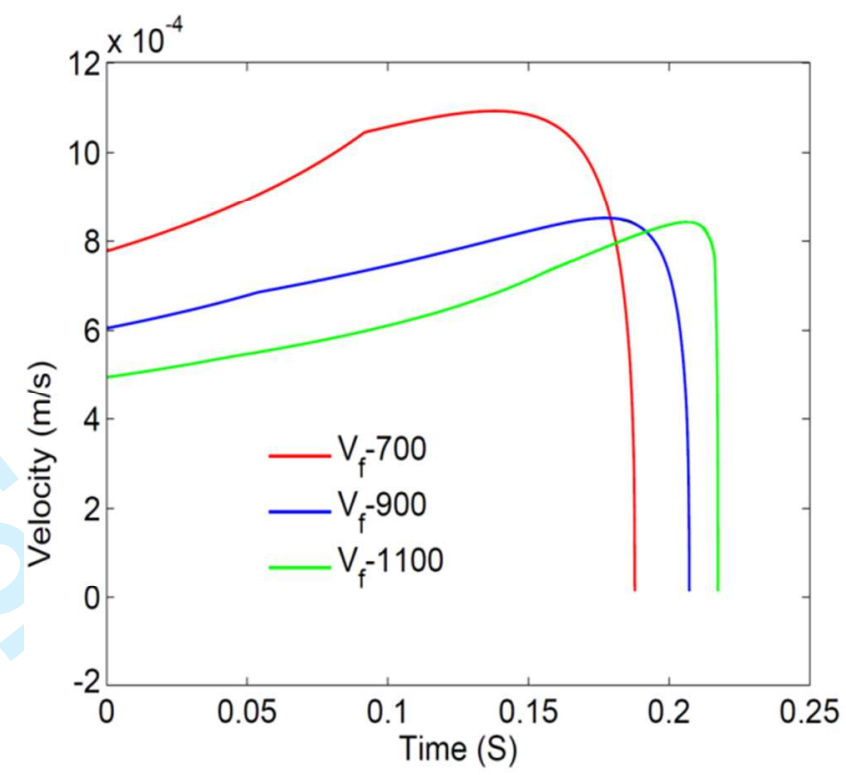

Figure 8 Variation of velocity of evaporated fuel $(\mathrm{m} / \mathrm{s})$ for different droplet diameters 

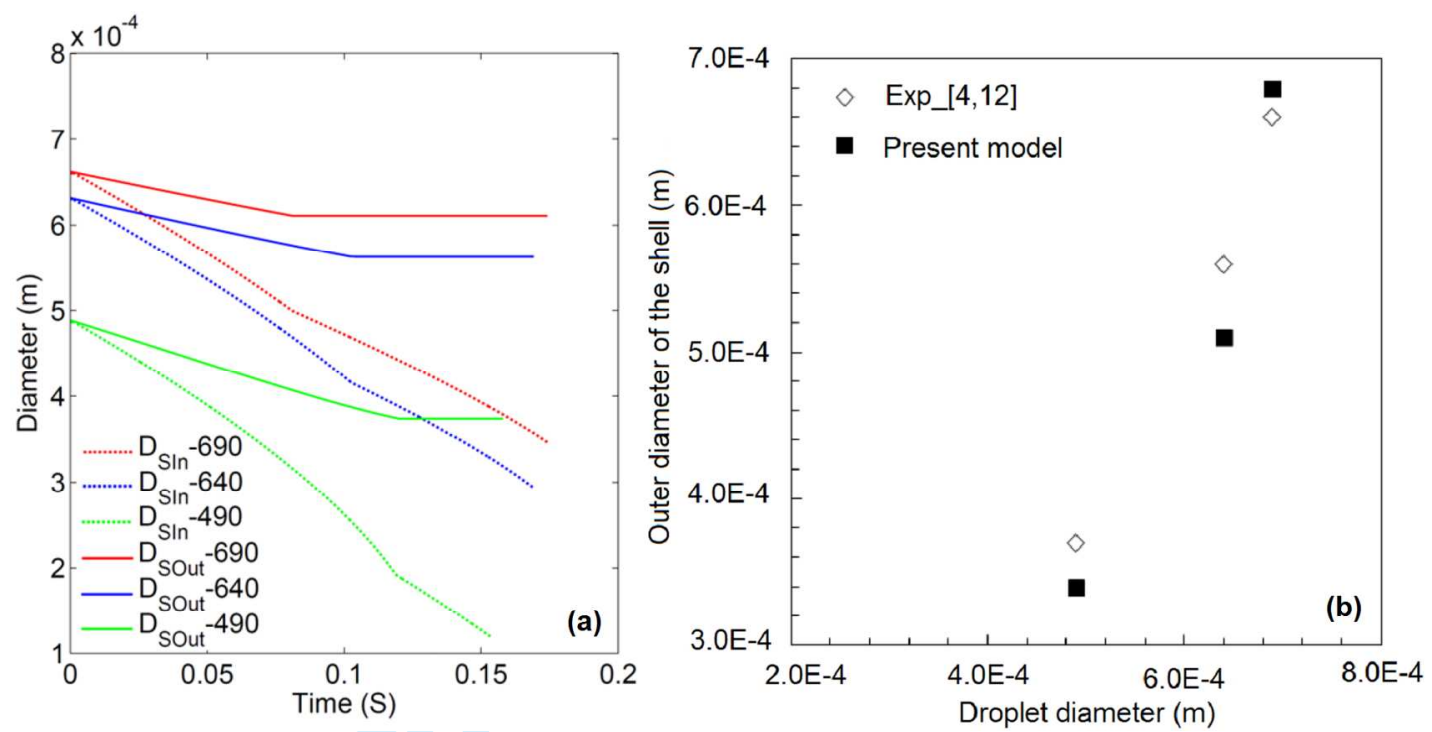

Figure 9 (a) Variation of shell dimension of EPRI 4011 of Urban et al., [4, 12] and (b) Comparison of present model with experimental results of Urban et al., [4, 12] 
Table 1 Fuel properties used in the numerical model and Dryer [12]

\begin{tabular}{|c|c|c|}
\hline Property & Present fuel & EPRI 4011 [12] \\
\hline Density at $288 \mathrm{~K}\left(\mathrm{~kg} / \mathrm{m}^{3}\right)$ & 990 & 970 \\
\hline Specific gravity (oAPI) & 12.9 & \\
\hline Surface Tension at $293 \mathrm{~K}(\mathrm{~N} / \mathrm{m})$ & 0.0284 & \\
\hline Pour point $\left({ }^{\circ} \mathrm{C}\right)$ & $9-12$ & \\
\hline Flash pint $\left({ }^{\circ} \mathrm{C}\right)$ & $60-99$ & \\
\hline Kinematic viscosity at $40^{\circ} \mathrm{C}(\mathrm{cSt})$ & 617.7 & \\
\hline Boiling point $\left({ }^{\circ} \mathrm{C}\right)$ & 550 & \\
\hline Carbon (\%mass) & 84.0 to 87.0 & 85.7 \\
\hline Hydrogen (\%mass) & 10.3 to 11.5 & 10.1 \\
\hline Sulfur (\%mass) & 2.35 to $3.8 \%$ & 2.31 \\
\hline Oxygen (\%mass) & 0.037 to 0.053 & \\
\hline Nitrogen (\%mass) & 0.023 to 0.04 & 0.43 \\
\hline Ash (\%mass) & 0.03 to 0.053 & 0.07 \\
\hline CCR (\%wt) & 16.0 & \\
\hline Max. Asphaltene content (\%wt) & 16.0 & 10.35 \\
\hline Nickel (ppm) & 42 & 297 \\
\hline Vanadium (ppm) & 130 & \\
\hline (HHV) (MJ/kg) & 43.6 & \\
\hline$(\mathrm{LHV})(\mathrm{MJ} / \mathrm{kg})$ & 41 to 42.5 & \\
\hline
\end{tabular}


Table 2 Kinetic parameters of the P2 asphaltene cracking model of Phillips et al. [10]

\begin{tabular}{|c|c|c|}
\hline & Activation energy $\left(\mathrm{E}_{\mathrm{a}}\right)(\mathrm{kJ} / \mathrm{mol})$ & Frequency factor $(\mathrm{A})\left(\mathrm{s}^{-1}\right)$ \\
\hline $\mathrm{k}_{1}$ & 195 & $1.16 \times 10^{13}$ \\
\hline $\mathrm{k}_{2}$ & 273 & $4.99 \times 10^{19}$ \\
\hline $\mathrm{k}_{3}$ & 263 & $1.41 \times 10^{14}$ \\
\hline $\mathrm{k}_{4}$ & 241 & $1.91 \times 10^{17}$ \\
\hline $\mathrm{k}_{5}$ & 247 & $4.04 \times 10^{14}$ \\
\hline $\mathrm{k}_{6}$ & 240 & $3.79 \times 10^{18}$ \\
\hline
\end{tabular}




\section{List of Figures}

Figure 1 The P2 model of the asphaltene cracking mechanism of Phillips et al. [10]

Figure 2 The stages of droplet evaporation, shell formation and final cenosphere formation

Figure 3 (a) Radial temperature distribution in the droplet; (b) Variation of reaction rate constants

Figure 4 Pressure balance for $P r_{p f}$ and $\operatorname{Pr}_{C}$

Figure 5 (a) Variation in outer diameter $\left(D_{\text {SOut }}\right)$, inner diameter $\left(D_{S I n}\right)$ of the shell, droplet diameter $\left(D_{I n}\right)$ and (b) Variation in the thickness (h) of the shell in relation to differen droplet diameters

Figure 6 Variations in (a) fuel evaporation and (b) gas formation for different droplet diameters

Figure 7 Variations in (a) coke formation and (b) coke accumulation for different droplet diameters

Figure 8 Variation of velocity of evaporated fuel $(\mathrm{m} / \mathrm{s})$ for different droplet diameters

Figure 9 (a) Variation of shell dimension of EPRI 4011 of Urban et al., [4, 12] and (b) Comparison of present model with experimental results of Urban et al., [4, 12] 


\section{List of Tables}

Table 1 Fuel properties used in the numerical model and Dryer [12]

Table 2 Kinetic parameters of the P2 asphaltene cracking model of Phillips et al. [10] 


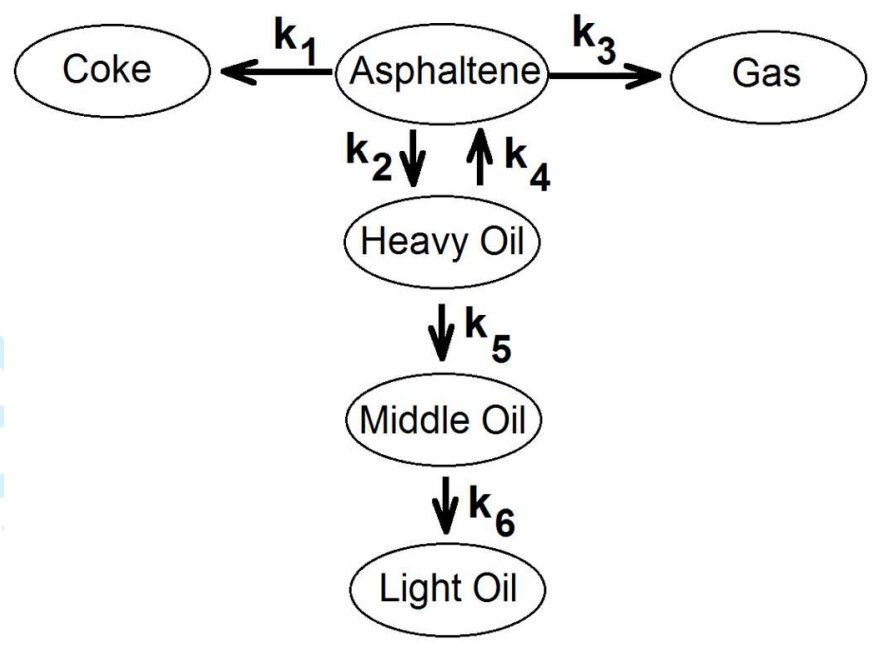

Figure 1 The P2 model of the asphaltene cracking mechanism of Phillips et al. [10] 


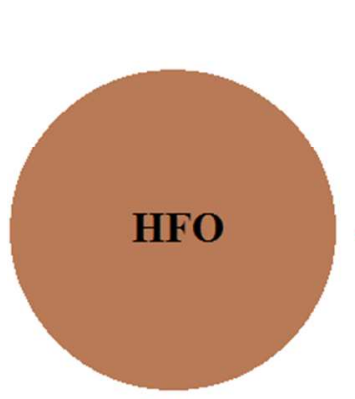

(a)

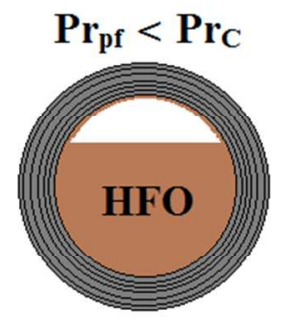

(d)

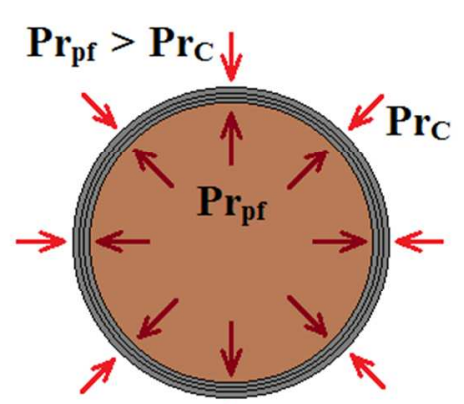

$\uparrow$ (b)

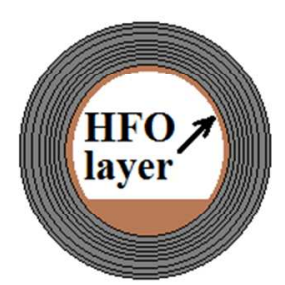

(e)

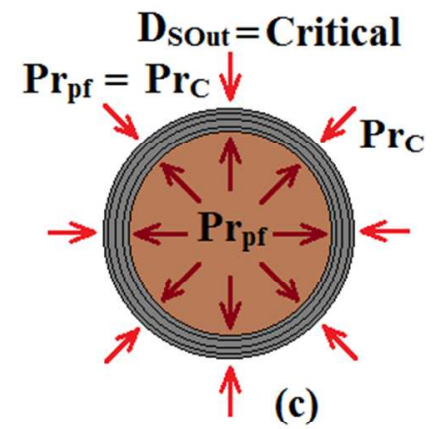

Cenosphere

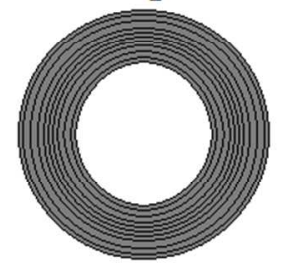

(f)

Figure 2 The stages of droplet evaporation, shell formation and final cenosphere formation 

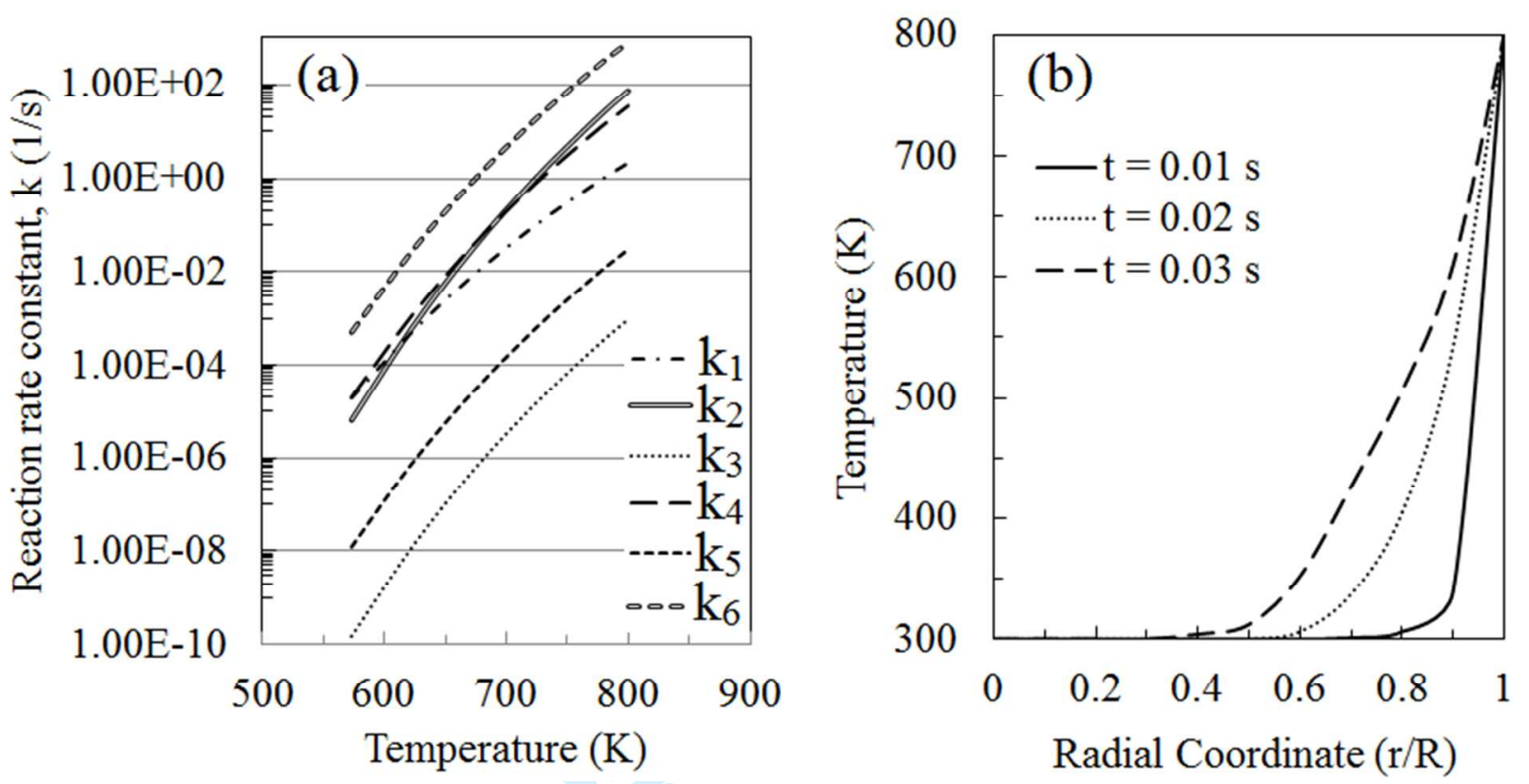

Figure 3 (a) Radial temperature distribution in the droplet; (b) Variation of reaction rate constants 


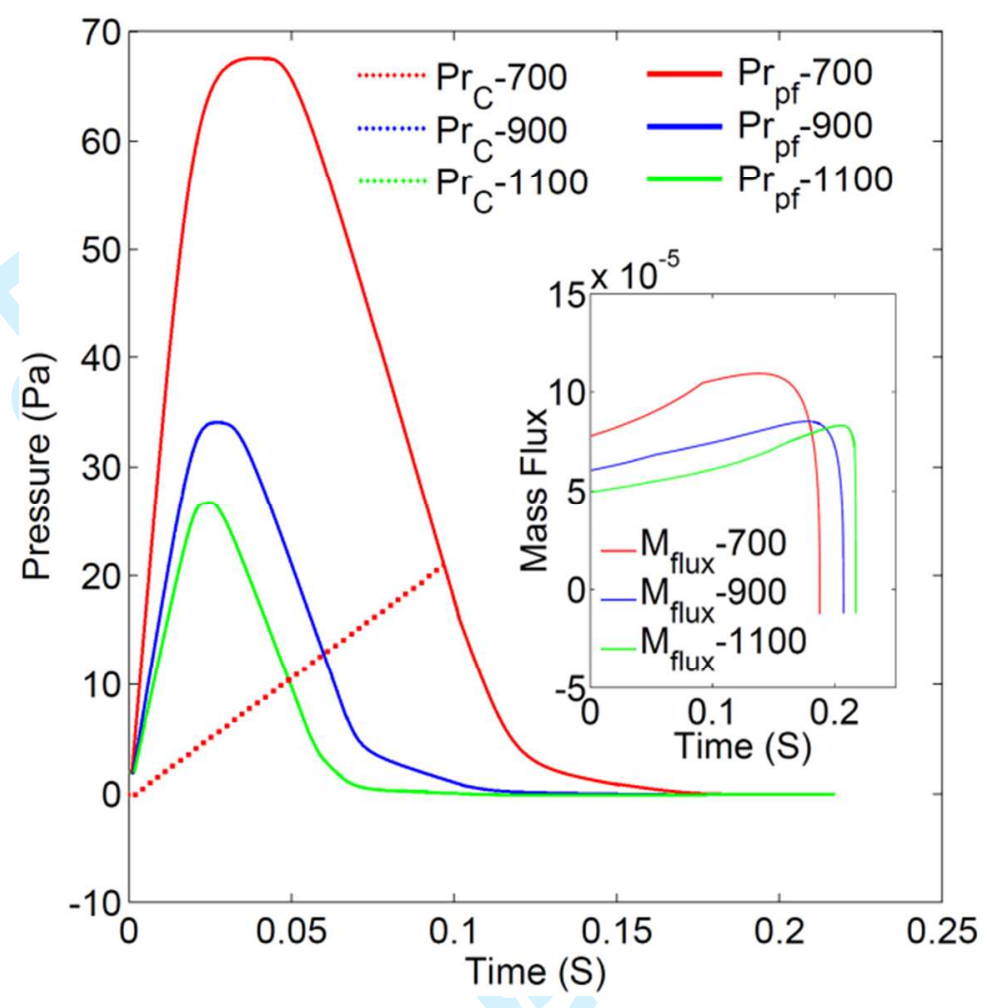

Figure 4 Pressure balance for $P r_{p f}$ and $P r_{C}$ 

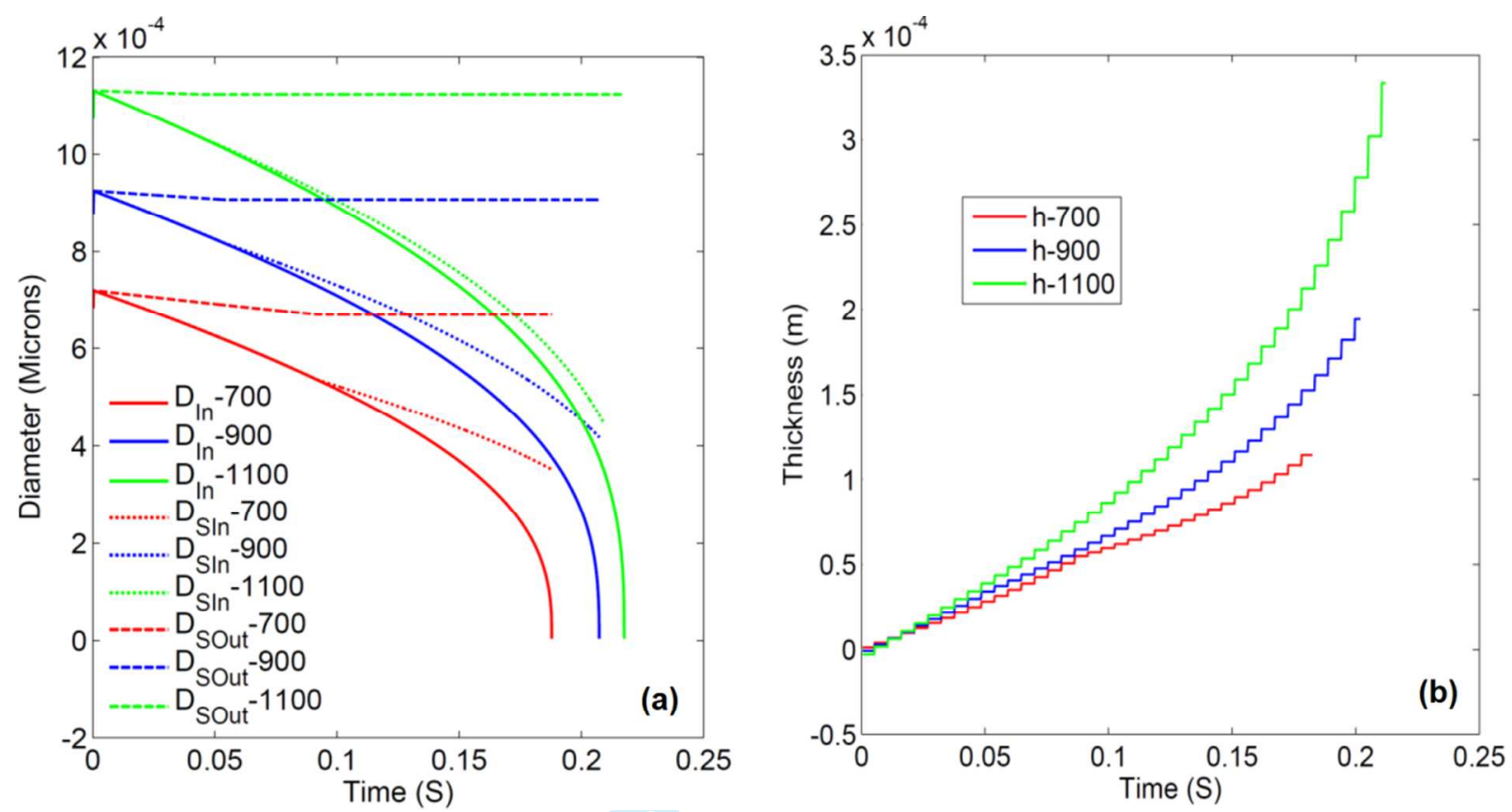

Figure 5 (a) Variation in outer diameter $\left(D_{\text {Sout }}\right)$, inner diameter $\left(D_{S I n}\right)$ of the shell, droplet diameter $\left(D_{I n}\right)$ and (b) Variation in the thickness (h) of the shell in relation to differen droplet diameters 

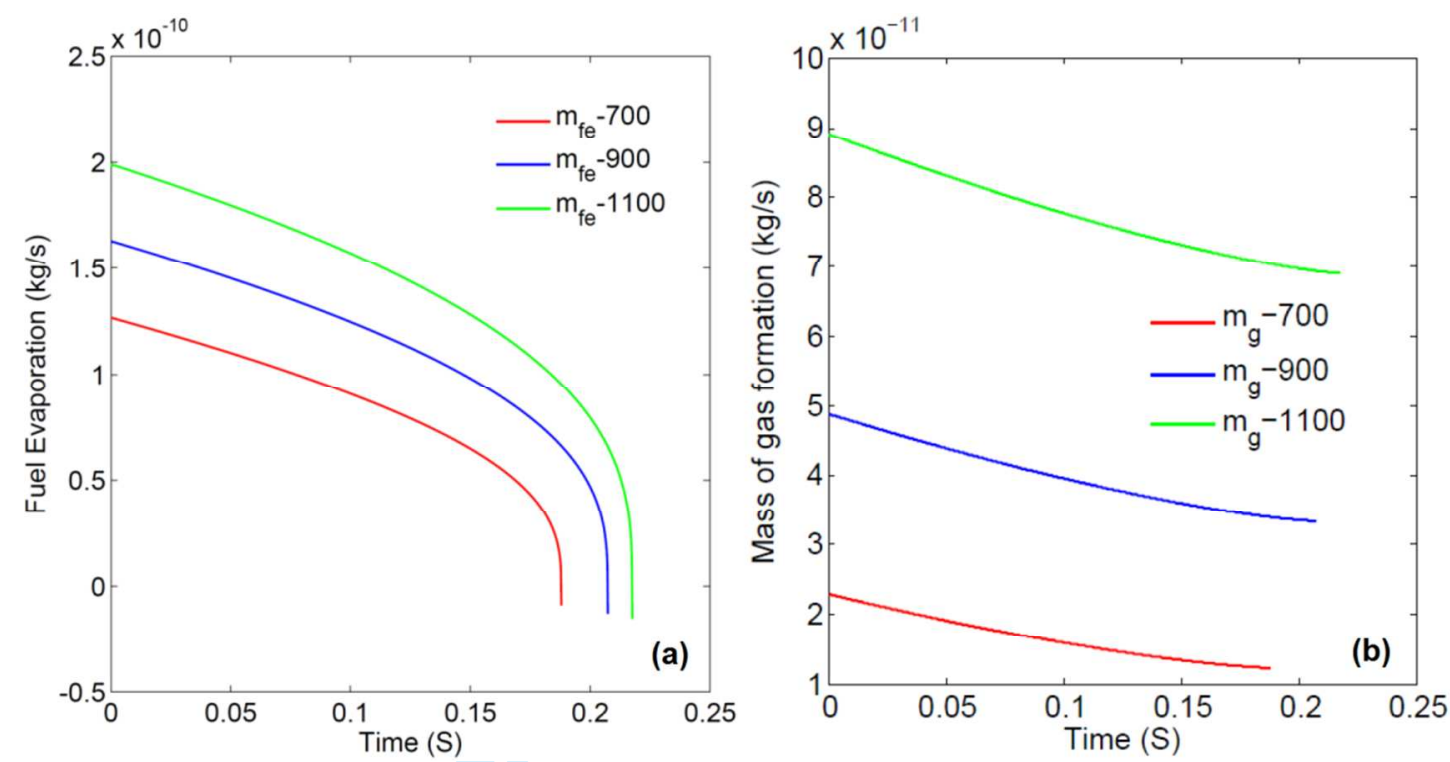

Figure 6 Variations in (a) fuel evaporation and (b) gas formation for different droplet diameters 

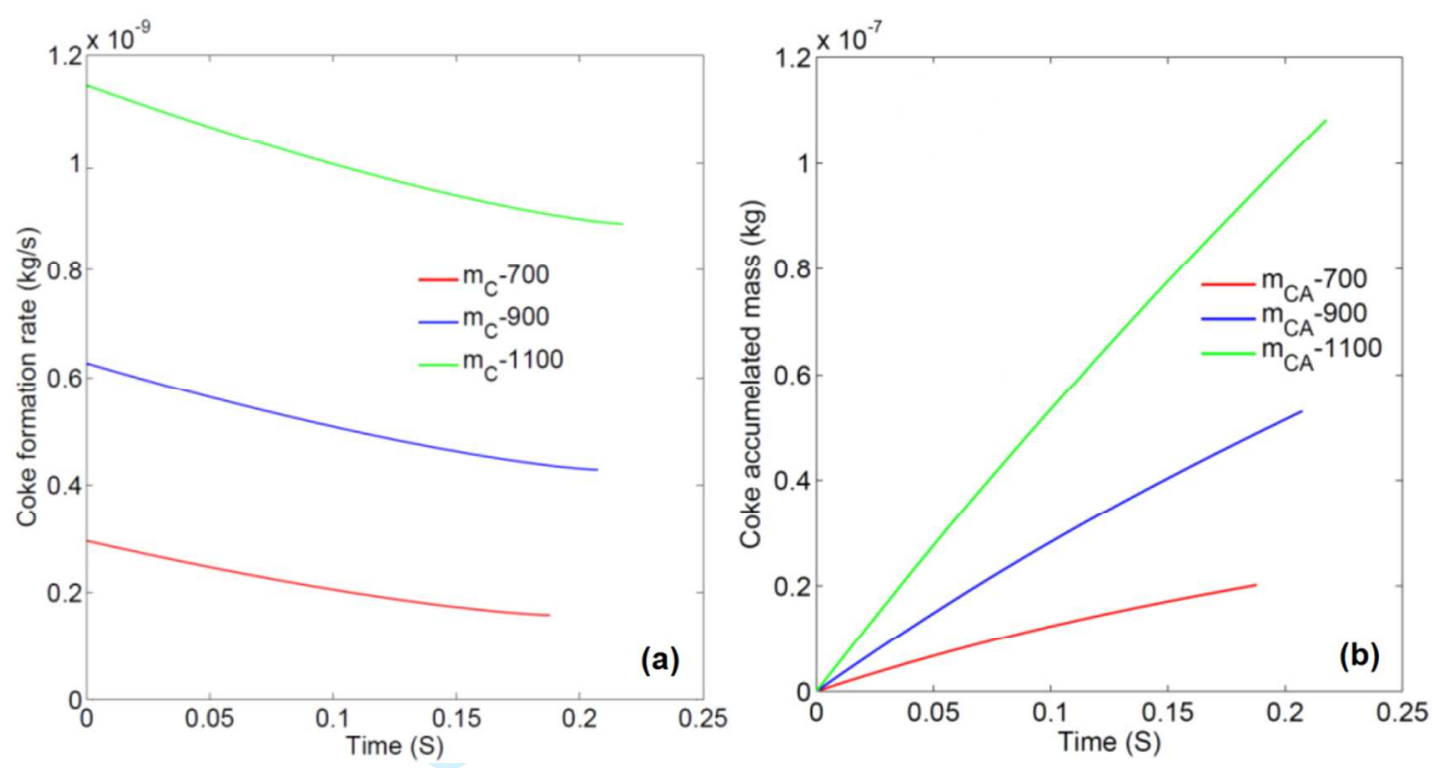

Figure 7 Variations in (a) coke formation and (b) coke accumulation for different droplet diameters 


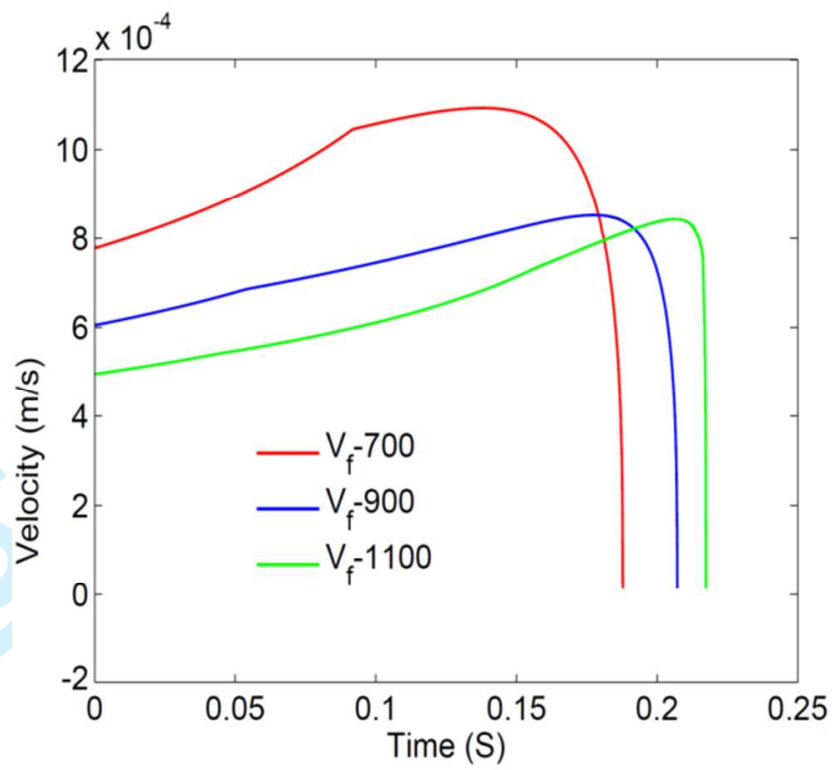

Figure 8 Variation of velocity of evaporated fuel $(\mathrm{m} / \mathrm{s})$ for different droplet diameters 

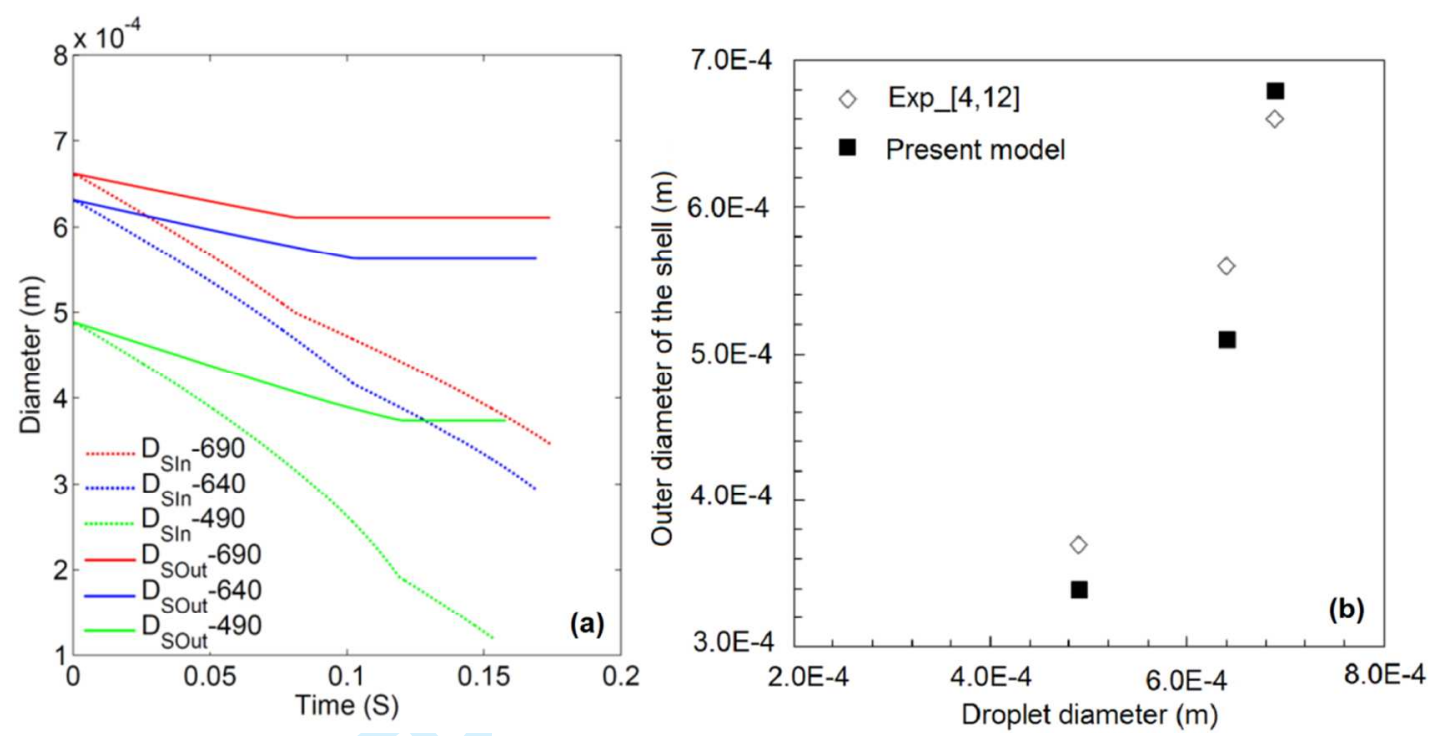

Figure 9 (a) Variation of shell dimension of EPRI 4011 of Urban et al., [4, 12] and (b) Comparison of present model with experimental results of Urban et al., $[4,12]$ 
Table 1 Fuel properties used in the numerical model and Dryer [12]

\begin{tabular}{|c|c|c|}
\hline Property & Present fuel & EPRI 4011 [12] \\
\hline Density at $288 \mathrm{~K}\left(\mathrm{~kg} / \mathrm{m}^{3}\right)$ & 990 & 970 \\
\hline Specific gravity (oAPI) & 12.9 & \\
\hline Surface Tension at $293 \mathrm{~K}(\mathrm{~N} / \mathrm{m})$ & 0.0284 & \\
\hline Pour point $\left({ }^{\circ} \mathrm{C}\right)$ & $9-12$ & \\
\hline Flash pint $\left({ }^{\circ} \mathrm{C}\right)$ & $60-99$ & \\
\hline Kinematic viscosity at $40^{\circ} \mathrm{C}(\mathrm{cSt})$ & 617.7 & \\
\hline Boiling point $\left({ }^{\circ} \mathrm{C}\right)$ & 550 & \\
\hline Carbon (\%mass) & 84.0 to 87.0 & 85.7 \\
\hline Hydrogen (\%mass) & 10.3 to 11.5 & 10.1 \\
\hline Sulfur (\%mass) & 2.35 to $3.8 \%$ & 2.31 \\
\hline Oxygen (\%mass) & 0.037 to 0.053 & \\
\hline Nitrogen (\%mass) & 0.023 to 0.04 & 0.43 \\
\hline Ash (\%mass) & 0.03 to 0.053 & 0.07 \\
\hline CCR (\%wt) & 16.0 & \\
\hline Max. Asphaltene content (\%wt) & 16.0 & 10.35 \\
\hline Nickel (ppm) & 42 & 297 \\
\hline Vanadium (ppm) & 130 & \\
\hline (HHV) (MJ/kg) & 43.6 & \\
\hline$(\mathrm{LHV})(\mathrm{MJ} / \mathrm{kg})$ & 41 to 42.5 & \\
\hline
\end{tabular}


Table 2 Kinetic parameters of the P2 asphaltene cracking model of Phillips et al. [10]

\begin{tabular}{|c|c|c|}
\hline & Activation energy $\left(\mathrm{E}_{\mathrm{a}}\right)(\mathrm{kJ} / \mathrm{mol})$ & Frequency factor $(\mathrm{A})\left(\mathrm{s}^{-1}\right)$ \\
\hline $\mathrm{k}_{1}$ & 195 & $1.16 \times 10^{13}$ \\
\hline $\mathrm{k}_{2}$ & 273 & $4.99 \times 10^{19}$ \\
\hline $\mathrm{k}_{3}$ & 263 & $1.41 \times 10^{14}$ \\
\hline $\mathrm{k}_{4}$ & 241 & $1.91 \times 10^{17}$ \\
\hline $\mathrm{k}_{5}$ & 247 & $4.04 \times 10^{14}$ \\
\hline $\mathrm{k}_{6}$ & 240 & $3.79 \times 10^{18}$ \\
\hline
\end{tabular}




\title{
Cenosphere formation from heavy fuel oil: A numerical analysis accounting for the balance between porous shells and internal pressure
}

\author{
V. Mahendra Reddy ${ }^{1}$, Mustafa M. Rahman², Appala N. Gandi ${ }^{3}$, A. M. Elbaz ${ }^{1,4}$, \\ Robert A. Schrecengost ${ }^{5}$, William L. Roberts ${ }^{1^{*}}$ \\ ${ }^{1}$ Clean Combustion Research Center, King Abdullah University of Science and Technology, \\ Thuwal, Saudi Arabia \\ ${ }^{2}$ Mechanical Engineering Program, PSE Division, King Abdullah University of Science and \\ Technology, Thuwal, Saudi Arabia \\ ${ }^{3}$ Computational Physics \& Materials Science, PSE Division, King Abdullah University of \\ Science and Technology, Thuwal, Saudi Arabia \\ ${ }^{4}$ Mechanical power department, Faculty of Engineering Materia, Helwan University, Cairo, \\ Egypt \\ ${ }^{5}$ Alstom Power Inc. Windsor CT, USA
}

\begin{abstract}
:
Heavy fuel oil (HFO) as a fuel in industrial and power generation plants ensures the availability of energy at economy. Coke and cenosphere emissions from HFO combustion need to be controlled by particulate control equipment such as electrostatic precipitators, and collection effectiveness is impacted by the properties of these particulates. The cenosphere formation is a function of HFO composition, which varies depending on the source of the HFO. Numerical modeling of the cenosphere formation mechanism presented in this paper is an economical method of characterizing cenosphere formation potential for HFO in comparison to experimental analysis of individual HFO samples, leading to better control and collection.

\footnotetext{
1william.roberts@kaust.edu.sa; Phone: +966 12 808-4909
} 
In the present work, a novel numerical model is developed for understanding the global cenosphere formation mechanism. The critical diameter of the cenosphere is modeled based on the balance between two pressures developed in an HFO droplet. First is the pressure $\left(\operatorname{Pr}_{p f}\right)$ developed at the interface of liquid surface and inner surface of the accumulated coke due to the flow restriction of volatile components from the interior of the droplet. Second is the pressure due to the outer shell strength $\left(P r_{C}\right)$ gained from van der Walls energy of the coke layers and surface energy. In this present study it is considered that when $\operatorname{Pr}_{C} \geq P r_{p f}$ the outer shell starts to harden. The internal motion in the shell layer ceases and the outer diameter $\left(D_{\text {Sout }}\right)$ of the shell is then fixed.

The entire process of cenosphere formation in this study is analyzed in three phases: regression, shell formation and hardening, and post shell hardening. Variations in pressures during shell formation is analyzed. Shell (cenosphere) dimensions are evaluated at the completion of droplet evaporation. The rate of fuel evaporation, rate of coke formation and coke accumulation are analyzed. The model predicts shell outer diameters of 650,860 and $1040 \mu \mathrm{m}$, and inner diameters are 360, 410 and $430 \mu \mathrm{m}$ respectively, for 700, 900 and $1100 \mu \mathrm{m}$ HFO droplets. The present numerical model is validated with experimental results available from the literature. Total variation between computational and experimental results is in the range of 3 to $7 \%$.

\section{Introduction}

Heavy fuel oil (HFO) produces copious heat energy and is particularly useful in industrial settings and electric power stations [1]. Soot formation of carbonaceous particulates from HFO combustion results in ultrafine particles $(\sim 0.1 \mu \mathrm{m})$ and can cause adverse health effects in 
humans [2, 3]. Apart from health concerns, production of larger carbonaceous particulates known as cenospheres $(50-1000 \mu \mathrm{m})$ also results in increased fouling and corrosion of heat transfer surfaces, which increases equipment maintenance costs and downtime. Formation of cenospheres have been noted primarily in HFO combustion and generally this has been ascribed to the presence of asphaltenes in such fuels $[5,6]$. In general, emissions from HFO combustion systems are gaseous pollutants such as $\mathrm{CO}_{2}, \mathrm{CO}, \mathrm{SO}_{2}, \mathrm{NOx}$, etc., and carbonaceous particulates such as submicron soot and much larger cenospheres. Costly counter measures are required in the combustion process or for installation of air quality control systems to meet emissions standards [4].

When a droplet of HFO enters a combustor, heat causes vaporization of the volatiles, which eventually ignite and burn. A rise in temperature leads to cracking (pyrolysis) reactions and local formation of solids that accumulate on the surface of the droplet. The accumulated particles form a film that is permeable to volatiles, allowing continuous evaporation of the inner liquid. When all the volatiles have evaporated, the flame around the droplet runs out of fuel and dies out. The so-formed remaining hard structure is called a cenosphere [1]. The production of cenospheres has been observed in HFO combustion and has generally been ascribed to the presence of asphaltenes in the fuel [5]. Asphaltenes can be schematically described as aromatic units linked by alkyl chains. They are correspond to the part of the fuel which is soluble in benzene and insoluble in heptane [7]. Asphaltenes are the fraction of the oil that produces the highest amount of coke with activation energies of 94 to $135 \mathrm{~kJ} / \mathrm{mol}$ [6]. When the as-formed cenosphere is heated and subsequently ignites in an oxygen-poor atmosphere, it burns via a heterogeneous surface reaction. The reaction rate is limited by the oxygen supply. Sharp falls in temperature 
and oxygen concentration at the exit of the combustion chamber cause cenosphere combustion to cease, which allows its emission to the atmosphere and produces harmful unburned carbon particulate emissions.

Cenosphere formation has been studied experimentally and numerically. Experimental methods used to study cenosphere formation from HFO include sample collection from boilers, the suspended droplet method, and freely falling droplet techniques. However, the composition of HFO changes depending on the source, and cenosphere formation depends on HFO composition. Experimental methods that do not account for HFO composition can thus have limited value. Numerical modeling, on the other hand, can be useful in the analysis of the formation of cenospheres from a particular HFO. A few numerical studies on cenosphere formation in HFO have previously been conducted [1, 8, 9]. Highlights and assumptions of the Antaki [8], Lee and law [9], and Moszkowicz et al. [1] models are elaborated in the subsection.

\subsection{Previous models of cenosphere formation}

\section{Antaki's Model:}

Antaki [8] described constant-diameter burning in the presence of a continuously thickening, rigid porous shell with a regressing liquid surface. Antaki's model has been called the $\mathrm{d}^{3}-1$ aw and rigid porous shell. In his model, he assumed that the volume fraction of solid particles in the droplet is relatively high. Therefore during vaporization, the model assumes that the droplet has a porous shell of a fixed outer radius which is equal to the initial droplet radius. Due to vaporization, the surface of the inner liquid sphere regresses with the time, and consequently the shell thickness increases. For simplicity, the analysis of the model is subdivided into two 
sections. First section starts when the droplet first experiences a quiescent hot gas, and before vaporization begins. In the second section, the temperature of the droplet surface has increased to the boiling point temperature, with the assumption that the porous shell is at the liquid boiling temperature. All of the heat transferred from the gas is absorbed by liquid and leads to heating of the inner liquid sphere. He introduced a dimensionless "heating parameter" in solving the governing equations, where the heating parameter represents the ratio of sensible enthalpy increase of the inner sphere up to the liquid boiling temperature to the effective enthalpy of vaporization of the liquid. Based on this rigid porous shell model, he concluded that the limiting cases of large and small values of the heating parameter lead to different behaviors for internal droplet heating and liquid surface regression. Antaki's model suggests that solid particles agglomerate precisely when the liquid component is completely depleted. Experimental studies have shown that the shell formed with solid particles is hollow in structure $[1,4,6,9]$.

\section{Lee and Law's Model:}

Lee and Law [9] studied the behavior of a slurry droplets under different gasification regimes. A two-period model was developed for droplet gasification leading to cenosphere formation. The model for the first period addresses the dimensional changes of the regressing droplet, and is obtained by equating the rate of liquid loss of a droplet with the gas-phase mass flow rate. According to this model, the square of the droplet size varies linearly with time (also known as $d^{2}$-law) and any residue of the burning process remains on the outer surface of the droplet where it accumulates. The thickness of this residue layer increases and porosity of the residue decreases with time. The model postulates that when both the layer porosity and thickness reach their respective critical values, the residual particles are sufficiently packed and results in a stable, rigid shell around the remaining droplet. At this point in time the second period begins, where 
the gasification of liquid occurs at a constant rate through the porous rigid shell and the outer shell radius remains constant. Vaporization of liquid results in creation of vapor-saturated volume within the shell.

Lee and Law also studied the nature of the pores in the outer shell in this period considering two cases: (a) pores of the shell are dry and saturated with vapor (dry), and (b) pores of the shell are wet and saturated with liquid fuel (wet). They concluded that the results from wet shell configuration are more realistic, and are discussed in the following. Assuming a spherical volume at the center of the shell for the vapor and using the liquid mass conservation, this model predicts that the cube of the inner diameter of the shell varies linearly with time, in agreement with the $\mathrm{d}^{3}$-law of Antaki's model, but with a different proportionality constant. This process occurs until the all the gasification and burning of the liquid is complete. At the end of this process, a porous and hallow cenosphere is formed with a spherical void in the center, in agreement with experimental observations. This model obeys conservation of mass in the slurry.

\section{Moszkowicz et al. Model}

A complementary model developed by Moszkowicz et al. describes the dimensional changes of cenosphere formation during a very fast pyrolysis of heavy fuel droplets. In this model it is assumed that the liquid fuel passes through an inert gas in a boiler. The heat transfer through the tube wall is dominated by conduction. The heat transfer between the inert gas and the liquid fuel is dominated by convention. There are two main parameters in this model: (a) evaporation kinetics of liquid heavy fuel, (b) solid coke formation by pyrolysis of the liquid. Experimentally it is observed that a solid residue is formed in the form of hollow spheres, with a diameter approximately twice that of the original droplets at the end of the fast pyrolysis. The shell thickness is extremely thin. In contrast to the solid constituents in the slurry in Lee and Law 
Model, the solid residues are products of hydrocarbon cracking of the liquid fuel in the experiments carried by Moszkowicz et al. [1]. Hence the rate of coke accumulation on the surface depends on the solid content in the liquid and the vaporization rate of the liquid. The solids accumulate on the liquid droplet surface until they reach a critical thickness around the droplet. Once this critical thickness is acheived, they form a porous shell of constant thickness around the droplet. Further cracking of hydrocarbons causes the expansion of the porous shell. This happens due to a mechanical equilibrium between the overpressure due to vaporization of the liquid within the shell and the pressure loss due to the flow of vapors through the porous shell. A gas bubble forms within the shell, which grows until the last hydrocarbons crack in the liquid phase and the bubble completely fills the volume within the shell. The end product is a hollow cenosphere whose thickness is equal to the critical thickness. The constituents of the liquid fuel determine the final diameter. An Arrhenius law is employed to determine the coke formation rate as a function of temperature, and a spherical shape is assumed for the droplet. Each droplet leads to the formation of a single cenosphere. The value of the critical shell thickness, $0.4 \mu \mathrm{m}$, is derived from experimental observations. $\mathrm{s}$

A primary difference between the Moszkowicz Model and the Lee and Law Model is that the first assumed a critical shell thickness and the second assumed a constant critical diameter. In the Moszkowicz Model, as soon as this critical thickness is reached, internal coke deposits contribute to an increase in the diameter of the shell. The deformation process is very fast while the mechanical properties of the shell remain unknown.

A few studies have considered the direct asphaltene-to-coke reaction $[1,8,9]$ because the asphaltene in HFO droplets reacts differently in different temperature zones within the droplet, producing some combination of gas, coke, middle oil and light oil [10, 11]. The influence of 
these products on the rate of coke formation has not yet been fully considered. Neither Lee and Law [9] nor Moszkowicz et al. [1] proposed a shell formation mechanism in their models, described above. Here, a numerical model is developed to clarify the mechanism that leads to cenosphere formation from the evaporation/combustion of HFO. The critical diameter of the cenosphere is not assumed, but rather modeled based on the balance between two pressures, the pressure developed due to the flow of evaporated fuel through the porous shell and the pressure on the shell due to the van der Walls energy of the coke layers and the surface energy. Three different sized droplets of 700, 900 and $1100 \mu \mathrm{m}$ are considered in the model. Variations in pressures during shell formation and shell dimensions are analyzed and compared. The rates of fuel evaporation, asphaltene reaction, product formation, coke formation and coke accumulation are also analyzed in relation to variations in the droplet diameter.

Table 1 Fuel properties used in the numerical model and Urban et al. [12]

The influence of the mass flux and the velocity of the evaporated fuel through the porous shells on the pressures during the shell formation stage are also studied. The present numerical model is validated using Urban et al.'s experimental results $[4,12]$. The properties of the fuel used in the numerical model presented here and in Urban et al.'s study are listed in the Table 1.

\section{Asphaltene reaction}

Several studies on the cracking of asphaltenes have been reported in the literature. Moschopedis et al. [13], Hayashitani et al. [14, 15], Phillips et al. [7], and Koseoglu and Phillips [11] have developed popular reaction mechanisms that lead to asphaltene cracking. They correlated the reaction rate constants for each of the reaction mechanisms with an Arrhenius-type expression. 
In this study, the P2 model of Phillips et al. [10] is used for asphaltene reactions in HFO droplets. This model [10] includes all six pseudo-components: coke, asphaltenes, heavy oils, middle oils, light oils and gases. The reaction model is shown in Fig. 1.

Figure 1 The P2 model of the asphaltene cracking mechanism of Phillips et al. [10]

The activation energies and the frequency factors for this model are given in Table 2. The kinetic reactions based on the Arrhenius equation at each component step are given in Eq. 1 to Eq. 6 . These equations (Eq.1 to Eq. 6) calculate the net mass of each component (light, medium, heavy oil, gas, coke and asphaltene) in the droplet after every time step ( $\partial t)$. During the droplet evaporation, the evaporation of light oil, middle oil and heavy oil are continuous processes along with coke and gas formation from asphaltene.

Table 2 Kinetic parameters of the P2 asphaltene cracking model of Phillips et al. [10]

$$
\begin{aligned}
& \dot{m}_{L O}=k_{6} m_{M O}-\dot{m}_{L O, \text { evap }} \\
& \dot{m}_{M O}=k_{5} m_{H F O}-\dot{m}_{M O, \text { evap }} \\
& \dot{m}_{H F O}=k_{2} m_{A}-k_{4} m_{H F O}-k_{5} m_{H F O}-\dot{m}_{H F O, \text { evap }} \\
& \dot{m}_{A}=k_{4} m_{H F O}-k_{2} m_{A}-k_{1} m_{A}-k_{3} m_{A} \\
& \dot{m}_{g a s}=k_{3} m_{A} \\
& \dot{m}_{\text {coke }}=k_{1} m_{A}
\end{aligned}
$$

\section{Mathematical Modeling}


With their multicomponent composition, HFO droplets possess individual physical and chemical properties. Evaporation, product formation from asphaltene, and coke accumulation on the surface of the droplet are simultaneous processes. The entire process of volatile matter evaporation and shell (cenosphere) formation is analyzed in three phases: regression, shell formation and hardening, and after shell hardening is completed.

As a consequence, transient heating of the droplet is considered. Assuming that droplet heating is spherically symmetric, the temperature distribution in the radial direction is calculated based on the conduction equation Eq. 7 [16-18]. The radial temperature gradient decreases with time.

Radial distribution of temperature in the droplet is described by:

$$
\frac{\partial \mathrm{T}}{\partial \mathrm{t}}=k\left(\frac{\partial^{2} \mathrm{~T}}{\partial R^{2}}+\frac{2}{R} \frac{\partial \mathrm{T}}{\partial \mathrm{R}}\right)
$$

The droplet is heated by convection from the surrounding hot gas. Additional heat transfer to the droplet helps with evaporation at the outer surface. The energy balance at the droplet outer surface is written as:

$$
h\left(T_{g}-T_{s}\right)=-\rho_{l} L \dot{R}_{d}+\left.k_{l} \frac{\partial T}{\partial R}\right|_{R=R_{d}}
$$

During the droplet regression, Eq. (8) is used as a boundary condition for Eq. (7) at outer surface of the droplet. The boundary condition at center of the droplet is a symmetry condition, namely:

$\left.\frac{\partial T}{\partial R}\right|_{R=0}=0$

The initial condition is taken as $T(t=0)=T_{0}(R)$

\subsection{Phase one: Regression Phase}


During the regression phase, the evaporation of the droplet follows Spalding's evaporation equations for a single fuel drop [9, 18-20]; governing conservation equations are shown in Eq. 8

to 11 .

$$
\begin{aligned}
& \dot{m}_{l}=\frac{\partial m_{l}}{\partial t}=-2 \pi D_{S i n} \frac{k_{l}}{C_{p_{l}}} \ln \left(1+B_{T}\right) \\
& B_{T}=\frac{c_{p v}\left(T_{g}-T_{s}\right)}{L\left(T_{s}\right)-\left(\left|\dot{q}_{d}\right| / \dot{m}_{l}\right)}
\end{aligned}
$$

Assuming unity Lewis number $(L e)$ and equal specific heat capacities for vapour $\left(c_{p v}\right)$ and gas

$$
\begin{aligned}
& \left(c_{p g}\right), \text { then } B_{T}=B_{M} . \\
& B_{M}=\frac{Y_{F_{S}}}{1-Y_{F_{S}}} \\
& \left.Y_{F_{S}}=\left[1+\left(\frac{P}{P_{F_{S}}}-1\right)\right) \frac{M_{A}}{M_{F}}\right]^{-1} \\
& P_{F_{S}}=\exp \left[a_{f}-\frac{b_{f}}{T_{S}-43}\right]
\end{aligned}
$$

During this phase, the mass of the accumulated coke on the surface of the droplet is low. Layer formation on the surface of the droplet due to coke accumulation is not considered until the total accumulated coke reaches a layer thickness of $10 \mu \mathrm{m}$.

At every time step, the radial temperature distribution and the radius of the droplet are calculated. The droplet is divided into ten annular spherical zones (volumes) of the same thickness $\left(L_{Z}=10 \times d r\right)$. The average temperature $\left(T_{Z, a v g}=\frac{1}{10} \sum T_{Z i}\right)$ and mass of the each spherical layer are calculated. The reaction rate constants $\left(k_{n}\right)$ in the each annular zone $\left(Z_{i}\right)$ is calculated according to the zone's average temperature $\left(T_{Z, a v g}\right)$. The asphaltene reaction and rate of formation of its products in the each layer are calculated. The evaporated liquid fuel (HFO, middle oil and light oil) and the gas formed from asphaltene undergo combustion. The initial 
stage of droplet evaporation and thin coke layer formation during regression period are shown in Fig. $2 \mathrm{a}$ and $\mathrm{b}$.

The shell inner diameter $\left(D_{\text {Sin }}\right)$ and outer diameter $\left(D_{\text {Sout }}\right)$ are calculated at each time step by following the Eq. 12 and $13[1,9]$.

Inner diameter of the shell: $D_{\operatorname{Sin}}=\sqrt[3]{\left(\frac{m_{L}}{\rho_{L}}\right) \frac{6}{\pi}}$

Outer diameter of the sphere: $D_{\text {Sout }}=\sqrt[3]{\left(\frac{m_{L}}{\rho_{L}}+\frac{m_{C A}}{\rho_{C A}}\right) \frac{6}{\pi}}$

\subsection{Phase two: Shell formation and hardening}

After the regression phase, the considerable amount of coke accumulated on the surface of the droplet forms a flexible and porous thin layer of coke. The evaporated fuel gases pass through the porous coke layer and develop pressure $\left(P r_{p f}\right)$ at the interface of droplet liquid surface and inner surface of the coke layer. The outer coke shell may expand due to the force due to $P r_{p f}$. The $P r_{p f}$ is calculated by using the momentum equation in spherical porous medium (Eq. 14) $[21,22]$. The porosity of the shell is considered constant, and that the coke particles are angular grains resulting in a porosity of $39 \%$.

$$
\frac{\rho^{f}}{\varepsilon}\left[\frac{\partial u_{i}}{\partial t}+\frac{\partial}{\partial x_{i}}\left(\frac{u_{i} u_{j}}{\varepsilon}\right)\right]=-\frac{1}{\varepsilon} \frac{\partial}{\partial x_{i}}\left(P r_{p f} \varepsilon\right)+\frac{\mu_{e}}{\varepsilon} \frac{\partial^{2} u_{i}}{x_{i}^{2}}-\frac{\mu^{f} u_{i}}{k}-\frac{1.75}{\sqrt{150}} \frac{\rho^{f}}{\sqrt{k}} \frac{|u|}{\varepsilon} u_{i}
$$

At the same time, because of the continuous evaporation of the droplet, the coke shell may also contract due to reduction in the diameter of the liquid droplet. However, the coke shell has its own strength $\left(\mathrm{Pr}_{C}\right)$ due to combined pressures from the compaction pressure between coke particles $\left(P_{M E L}\right)$, surface energy $\left(P_{S E L}\right)$ and van der Waals attraction $\left(P_{v d W}\right)$.

The self-compaction pressure of the layer [23, 24] 


$$
P_{M E L}=\sum_{N=1}^{j} \frac{2 E h^{2}}{\sqrt{3\left(1-v^{2}\right)}\left(R_{L}\right)^{2}}
$$

Here $h$ is the thickness of the each layer, $N$ is the number of layers formed till that time and $R_{L}$ is the Radius of the $n^{\text {th }}$ layer from the center.

Thickness of the coke layer for a period of time: $\frac{\dot{m}_{C A} N d t}{\rho_{C A}}=\frac{\pi}{6}\left[\left(2 h+D_{S i n}\right)^{3}-D_{S_{i n}}{ }^{3}\right]$

$R_{L}=\frac{D_{\operatorname{Sin}}}{2}+\sum_{N=1}^{k-1} h_{N}+\frac{h_{N}}{2}$

Compaction pressure due to surface energy [23, 24]

$P_{S E L}=\sum_{N=1}^{j} 2 A R_{L}^{-2.83}$

Pressure due to van der Waals bonding $[23,24]$

$P_{v d W}=\sum_{N=1}^{(j-1)} \frac{C_{33}}{6}\left[\left(\frac{\sigma}{\alpha}\right)^{10}-\left(\frac{\sigma}{\alpha}\right)^{4}\right]$

Total compaction pressure in the layers

$\operatorname{Pr}_{C}=P_{M E L}+P_{S E L}+P_{v d W}$

The pressure developed due to the flow of evaporated fuel through the porous shell $\left(P r_{p f}\right)$ and that from the pressure on the shell due to the van der Walls energy of the coke layers and the surface energy $\left(P r_{C}\right)$ are compared at each time step. Coke formation is a continuous process and accumulates on the surface of the droplet. Therefore, the mass and total pressure of the coke increase with time. At the same time, the droplet surface area decreases and the mass of the evaporated fuel decreases with time. This may cause the pressure due to flow in the porous shell to be reduced. At one point the $P r_{C}$ starts to dominate the $P r_{p f}$. At that point, shell expansion 
ceases and the outer surface of the shell becomes hard because there is no motion inside the shell and the heat from the surrounding combustion evaporates any remaining liquid fuel on the shell surface. The outer diameter of the shell (cenosphere) becomes fixed and reaches a critical diameter. The stages of pressure balance and when the shell reaches a critical diameter are shown in Fig. 2c.

Figure 2 The stages of droplet evaporation, shell formation and final cenosphere formation

\subsection{Phase three: Flow through rigid shell}

After hard shell formation, Lee and Law [9] assumed that because the total volume of the droplet is fixed by the rigid shell, the continuous depletion of the liquid due to gasification must create a continuously expanding, vapor-saturated space at the core of slurry inside the shell. This suggestion was idealized by assuming an expanding spherical vapor bubble embedded within the slurry mass of the droplet. Moszkowicz et al. [1] also made the same assumption. In the present analysis it is considered that the liquid in the shell occupies some portion of the shell and the remaining portion may be occupied by gas. Also it is assumed that in the combustor, droplets rotate because of one or a combination of the following reasons: the shear stress developed due to swirl flow or turbulence; rotational motion of the droplet from the nature of the injection; and temperature gradients in the vicinity of the droplet. Due to the spin or rotational motion of the droplet, liquid spreads on the inner surface of the shell and keeps the inner surface wet. Hence, it is assumed that the inner surface of the shell is spherical and covered with liquid fuel. The fuel spread in the porous shell evaporates due to the heat transfer from the surrounding combustion. It is assumed that inner surface of the shell is saturated with liquid that is flowing through porous 
shell. The outer surface of the shell is covered with saturated fuel vapor and hot combustion gases. Continuous evaporation of fuel takes place through this mechanism. Heat transfer and rate of evaporation is modeled with the following equation $[25,26]$.

$$
a_{l}\left[h_{s-g} \varepsilon\left(T_{g}-T_{S}\right)+h_{l-g} \varepsilon(1-\varepsilon)\left(T_{g}-T_{l}\right)\right]=L \dot{m}_{l S}+Q_{\text {Shell,Cond }}
$$

Here $h_{s-g}$ is the heat transfer coefficient between solid particles and fluid and $h_{l-g}$ is the heat transfer coefficient between liquid and gas.

$$
\begin{aligned}
& h_{s-g}=\left[2+1.1\left(\frac{\varepsilon \rho_{g} u_{g} d_{c}}{\mu_{f}}\right)^{0.6} \operatorname{Pr}^{1 / 3}\right] \frac{\lambda_{f}}{d_{c}} \\
& h_{l-g}=\left[2+1.1\left(\frac{\varepsilon \rho_{g} u_{g} d_{c}}{\mu_{f}}\right)^{0.6} \operatorname{Pr}^{1 / 3}\right] \frac{\lambda_{f}}{d_{p}} \frac{6(1-\varepsilon)}{d_{c}}
\end{aligned}
$$

The continuous process of evaporation and asphaltene reaction causes coke accumulation on the inner surface of the shell. The volume of the liquid is replaced by gas and finally a cenosphere forms. This phenomenon is shown in Figs. 2d, e and $\mathrm{f}$.

\section{Results and Discussion}

\subsection{Radial temperature distribution and reaction rate constants}

The variations in the reaction constants $\left(\mathrm{k}_{1}\right.$ to $\left.\mathrm{k}_{6}\right)$ at different temperatures are calculated according to Phillips et al.'s [10] kinetic parameters and are shown in Fig. 3a. The direct products from the asphaltene reaction are coke, gas and HFO. The reaction constant $\left(\mathrm{k}_{6}\right)$ for gas formation from asphaltene at any temperature is smaller than the other constants ( $\mathrm{k}_{1}$ to $\left.\mathrm{k}_{5}\right)$. Hence, 
Figure 3 (a) Radial temperature distribution in the droplet; (b) Variation of reaction rate constants

the probability of gas formation from asphaltene is less at any temperature. It is observed that the reaction constants increase with increased temperature. Therefore, the rate of reaction for all conversions will be faster in the outer layers of the droplet. The reaction constants for coke and HFO formation from asphaltene are almost the same at all temperatures. The middle oil formation rate constant is smaller, although it forms from HFO and the HFO concentration is high in the droplet. Therefore, middle oil formation from HFO is considerable. The boiling and evaporation characteristics for middle and light oil are not available in the literature. Hence it is assumed that the boiling and evaporation properties for these both (middle and light oil) are the same as kerosene.

The radial temperature distibution in the droplet is shown in Fig. 3b. The initial temperature of the droplet is $300 \mathrm{~K}$. In the present study it is assumed that the average temperature around the surface of the droplet is constant at $800 \mathrm{~K}$. The gas temperature immediately above the droplet surface is assumed to $1500 \mathrm{~K}$. The radial temperature distribution is analyzed and used before shell formation. At a time of $0.03 \mathrm{~s}$, high temperatures are observed in the outer layers. The inner layers are around room temperature $(300 \mathrm{~K})$. The kinetic reactions for asphaltene conversion take place only in the outer layers.

\subsection{Pressure balance due to coke accumulation and flow through porous shell}

At the initial stage of droplet evaporation, the thickness of the layer is not considered until a minimum amount of coke is accumulated on the outer surface of the droplet. After a certain 
amount of coke is accumulated on the surface of the droplet, a thin and porous layer is formed. The evaporated fuel flows through this porous layer. Coke formation and accumulation on the outer surface of the droplet are simultaneous with evaporation. Since the flow is restricted in porous coke, pressure $\left(P r_{p f}\right)$ develops at the interface of the liquid surface and the inner surface of the accumulated coke. The rate of fuel evaporation and the velocity of evaporated fuel passing through the porous shell influence the variation of $P r_{p f}$.

The variation of pressures at the interface of the droplet and coke shell is shown in Fig. 4. During the initial stage of evaporation, the droplet size is bigger and the fuel evaporation mass is high. Therefore, the mass flux of the evaporated fuel through the porous shell is increasing. Hence, the $\left(P r_{p f}\right)$ is increasing as well. At $25-50 \mathrm{~ms}$, as evaporation continues and begins to reduce the droplet size, the mass flux of the evaporated fuel and the velocities are also decreasing. At this point, the $P r_{p f}$ also starts to decrease. In bigger droplets, the inner surface area of the shell is high. However, in such droplets, the evaporation rate is also high and the mass flux of the evaporated fuel is less. Therefore, the pressure is lower for bigger droplets. The mass flux variation for the three droplet sizes is shown in the inset of the Fig. 4. The pressure due to shell strength $\left(P r_{C}\right)$ increases with increased thickness of the shell. The material properties and numerical relations for the three cases are the same. The variation in pressure is the same and follows the same trend in the three cases. It is considered that, when $P r_{C} \geq P r_{p f}$ the shell starts to harden and the mechanical strength of the shell dominates rather than van der Walls force or the surface tension. Therefore, variation in $\operatorname{Pr}_{C}$ after hard shell formation is not shown in Fig. 4.

Figure 4 Pressure balance for $P r_{p f}$ and $P r_{C}$ 


\subsection{Variation in shell diameters}

Variations in shell and droplet dimensions are shown in Fig. 5a. When the shell starts to harden $\left(P r_{C} \geq P r_{p f}\right)$, the internal motion (contraction and expansion) in the shell layer ceases and the outer diameter $\left(D_{\text {SOut }}\right)$ of the shell becomes fixed. Until this point, the droplet's diameter is equal to the shell inner diameter. Coke then accumulates on the inner surface of the shell. The continuous evaporation of the fuel reduces the droplet size. After the rigid shell begins to form, the rate of reduction in the shell's inner diameter is less than the rate of droplet diameter reduction. Hence, the droplet occupies less volume that then interior of the shell and rests at the bottom of the shell, as shown in Fig 2d. Lee and Law [9] considered that the droplet's diameter is equal to the shell's inner diameter. Lee and Law assumed that the evaporated liquid space is compensated by a bubble at the core of the droplet.

In this study, it is assumed that the droplet shape is distorted from a spherical geometry and that it rests in the shell as the liquid mass. Due to the spinning motion of the shell, the inner surface of the shell is wetted by the liquid drop. The inner surface of the shell is thus considered to be an effective evaporation surface of the liquid in the shell. For 700, 900 and $1100 \mu \mathrm{m}$ droplets, the shell outer diameters are 650,860 and $1040 \mu \mathrm{m}$, respectively. The shell inner diameters are 360, 410 and $430 \mu \mathrm{m}$, respectively.

Coke formation rate is a function of the rate of reaction of the droplet. For larger droplets the surface area is high and the temperature of the outer layers are also high, hence the mass of coke formation is high for larger droplets (shown in Fig. 4). The rate of decrease in shell inner 
diameter increases for larger droplets. The variation in thickness is increased for larger droplets. The variation in shell thickness is shown in Fig. 5b. The thickness of the shell for 700, 900 and $1100 \mu \mathrm{m}$ droplets are $1.15,1.95$ and $3.35 \mu \mathrm{m}$, respectively.

Figure 5 (a) Variation in outer diameter $\left(D_{\text {SOut }}\right)$, inner diameter $\left(D_{S I n}\right)$ of the shell, droplet diameter $\left(D_{\text {In }}\right)$ and (b) Variation in the thickness (h) of the shell in relation to different droplet diameters

\subsection{Droplet evaporation, gas and coke formation}

The variations in droplet evaporation, gas and coke formation from the asphaltene reaction are shown in Figs. 6 and 7. The surface area of the droplet during the regression period and the inner surface area of the shell (after rigid shell formation) are high for larger droplets. The rate of fuel evaporation is proportional to the surface area of the droplet. The rate of product formation is a function of the rate of asphaltene reaction. Therefore, fuel evaporation rate is higher for bigger droplets. The quantity of asphaltene at high temperatures is higher for larger droplets; hence, the rate of gas and coke formation from asphaltene is also higher for bigger droplets. The rate of gas formation at $\mathrm{t}=0.1 \mathrm{~s}$ is $1.6 \times 10^{-11}, 3.9 \times 10^{-11}$ and $7.8 \times 10^{-11} \mathrm{~kg} / \mathrm{s}$ for droplet sizes of 700,900 and $1100 \mu \mathrm{m}$, respectively. All evaporated products of light, middle and heavy oil and gas formed from asphaltene (except coke) are continuously undergoing combustion. The accumulation of coke during droplet evaporation is plotted in Fig. $7 \mathrm{~b}$. At the $\mathrm{t}=0.1 \mathrm{~s}$ instant of time, the fuel evaporation for 700,900 and $1100 \mu \mathrm{m}$ diameter droplets is $0.85 \times 10^{-10}, 1.25 \times 10^{-10}$ and $1.6 \times 10^{-10}$ $\mathrm{kg} / \mathrm{s}$, respectively. The coke accumulation up to $0.1 \mathrm{~s}$ of droplet evaporation is $0.125 \times 10^{-7}$, $0.29 \times 10^{-7}$ and $0.52 \times 10^{-7} \mathrm{~kg}$ for the cases of 700,900 and $1100 \mu \mathrm{m}$, respectively. 
Figure 6 Variations in (a) fuel evaporation and (b) gas formation for different droplet diameters

Figure 7 Variations in (a) coke formation and (b) coke accumulation for different droplet diameters

\subsection{Velocity of evaporated fuel through shell}

The evaporated fuel passes through the porous shell. The variations in the velocity of evaporated fuel through the shell for different sized droplets are shown in Fig. 8. At any instant in time, the inner diameter of the shell is higher for larger droplets and vice versa. Hence, the mass flux of evaporated fuel is higher for the case of smaller droplets. Therefore, high velocity is observed with small droplets. A drastic decrease in velocity is observed at the end of droplet evaporation. The reason is that the inner shell is considered as a wet surface in this study and evaporation takes place on that surface. At the end of droplet evaporation, the remaining small quantity of fuel reaches to near boiling point and quickly evaporates by spreading on the shell's inner surface. At $0.15 \mathrm{~s}$ for instance, the inner surface areas of the three droplets $(700,900$ and 1100 $\mu \mathrm{m})$ are $5.67 \times 10^{-7}, 1.28 \times 10^{-6}$ and $2.53 \times 10^{-6} \mathrm{~m}^{2}$, respectively. The outward velocity of the evaporated fuel for three droplets at this particular time is $10.8 \times 10^{-4}, 8.2 \times 10^{-4}$ and $7.1 \times 10^{-4} \mathrm{~m} / \mathrm{s}$, respectively.

Figure 8 Variation of velocity of evaporated fuel $(\mathrm{m} / \mathrm{s})$ for different droplet diameters

\section{Validation}


The present numerical model is validated with the experimental results of Urban and Dryer [4] and Urban et al. [12]. Properties of the fuel (EPRI 4011) used in Urban et al.'s [12] study are listed in the Table 1. In that study [12], a range of droplets (100 to $700 \mu \mathrm{m})$ of different fuels are tested and the variations in particle (cenosphere) diameter and droplet size are studied. To validate the model's results, droplets of 490, 640 and $690 \mu \mathrm{m}$ of EPRI 4011 fuel are considered and the particle diameter is calculated via the present model. Comparisons between the results from the computation model and experimental observations from Urban et al. [12] are shown in Fig. 9. The cenosphere diameters as given by the model are 340, 505, $670 \mu \mathrm{m}$ for 490, 640 and $690 \mu \mathrm{m}$ droplets, respectively. The experimental observations by Urban et al. [12] measured diameters of 360,545 and $655 \mu \mathrm{m}$ for 490,640 and $690 \mu \mathrm{m}$ droplets, respectively. The total variation between the present computational model and the experimental results of Urban et al. [12] is in the range of 3 to $7 \%$.

Figure 9 (a) Variation of shell dimension of EPRI 4011 of Urban et al., [4, 12] and (b) Comparison of present model with experimental results of Urban et al., [4, 12]

\section{Conclusions}

In the present work, a numerical model is developed to understand the mechanism of cenosphere formation from the evaporation/combustion of a heavy fuel oil (HFO) droplet. Asphaltene reactions in the different zones of the droplet are considered and the rates of formation of various products are analyzed. The critical diameter of the cenosphere is modeled based on the balance between two pressures developed during shell formation. 
1. The reaction constant $\left(\mathrm{k}_{6}\right)$ for gas formation from asphaltene is smaller than other constants $\left(\mathrm{k}_{1}\right.$ to $\left.\mathrm{k}_{5}\right)$. Hence, the probability of gas formation from asphaltene is less at all temperatures considered. The reaction rate constants increase with increasing temperature. The kinetic reactions for asphaltene conversion take place in the outer layers only.

2. When the shell starts to harden $\left(P r_{C} \geq P r_{p f}\right)$, the internal motion in the shell layer ceases and the outer diameter $\left(D_{\text {SOut }}\right)$ becomes fixed. The droplet resides completely within the shell and the liquid spreads on the inner surface and the shell acts as the effective evaporation surface. The shell's outer diameters for 700, 900 and $1100 \mu \mathrm{m}$ droplets are calculated to be 650,860 and $1040 \mu \mathrm{m}$, respectively and the resulting inner diameters are 360, 410 and 430 $\mu \mathrm{m}$, respectively.

3. Since the inner surface area of the shell is high for large droplets, fuel evaporation is high. The rate of coke formation is a function of mass of liquid fuel evaporation. At $t=0.1 \mathrm{~s}$, the fuel evaporation rate for 700,900 and $1100 \mu \mathrm{m}$ droplets is $0.85 \times 10^{-10}, 1.25 \times 10^{-10}$ and $1.6 \times 10^{-10} \mathrm{~kg} / \mathrm{s}$, respectively and the coke accumulation during the first $0.1 \mathrm{~s}$ is $1.25 \times 10^{-8}$, $2.9 \times 10^{-8}$ and $5.2 \times 10^{-8} \mathrm{~kg}$.

4. The mass flux of the evaporated fuel is high for smaller droplets. Therefore, a high vapor velocity is observed with small droplets. At $0.15 \mathrm{~s}$, the inner surface areas of the shells of the three droplets are $5.67 \times 10^{-7}, 1.28 \times 10^{-6}$ and $2.53 \times 10^{-6} \mathrm{~m}^{2}$, respectively, and the vapor velocity is $10.8 \times 10^{-4}, 8.2 \times 10^{-4}$ and $7.1 \times 10^{-4} \mathrm{~m} / \mathrm{s}$, respectively.

Acknowledgments: The authors gratefully acknowledge that this article is based upon research supported by Alstom (Switzerland) Ltd. and Alstom Power Inc. in collaboration with KAUST's Clean Combustion Research Center. 


\section{Nomenclature:}

\begin{tabular}{|c|c|}
\hline$a_{f}$ and $b_{f}$ & Constants in Eq. (13) \\
\hline$B_{M}$ & Mass diffusion transfer number \\
\hline$B_{T}$ & Thermal diffusion transfer number \\
\hline$C_{33}$ & Compressive constant \\
\hline$c_{p g}$ & Specific heat of gas (environment), (J/kg K) \\
\hline$C_{p_{l}}$ & Specific heat at constant pressure, $(\mathrm{J} / \mathrm{kg} \mathrm{K})$ \\
\hline$c_{p v}$ & Specific heat of vapour, $(\mathrm{J} / \mathrm{kg} \mathrm{K})$ \\
\hline$D_{\text {Sin }}(\mathrm{m})$ & Shell inner diameter, $(\mathrm{m})$ \\
\hline$D_{\text {Sout }}(\mathrm{m})$ & Shell outer diameter, $(\mathrm{m})$ \\
\hline$d_{c}$ & Mean diameter of the shell, (m) \\
\hline$E$ & Elastic modulus, $\left(\mathrm{N} / \mathrm{m}^{2}\right)$ \\
\hline$h$ & Heat transfer coefficient, Eq. (23), (m) \\
\hline$h$ & Thickness of each layer, Eq. (17), (m) \\
\hline$k$ & Thermal diffusivity, Eq. (7), $\left(\mathrm{m}^{2} / \mathrm{s}\right)$ \\
\hline$k$ & Permeability, Eq. (16), $\left(\mathrm{m}^{2}\right)$ \\
\hline$k_{l}$ & Thermal conductivity, in Eq. (8), J/ms K \\
\hline$k_{1,2,3,4,5,6}$ & Rate constants for Eq. (1) to Eq. (6) \\
\hline Le & Lewis number \\
\hline$M$ & Molecular weight \\
\hline$\dot{m}$ & Mass rate of reaction (converted or formed), Eq. (4), $(\mathrm{kg} / \mathrm{s})$ \\
\hline$\dot{m}_{\text {coke }}$ & Rate of coke formation, $(\mathrm{kg} / \mathrm{s})$ \\
\hline$\dot{m} \_$evap & Rate of evaporation of (HFO, LO, MO), (kg/s) \\
\hline$\dot{m}_{g a s}$ & Rate of gas formation, $(\mathrm{kg} / \mathrm{s})$ \\
\hline
\end{tabular}




\begin{tabular}{|c|c|}
\hline$m_{L}$ & Mass liquid in the droplet, $(\mathrm{kg})$ \\
\hline$m_{l}$ & Mass of liquid fuel evaporation from the droplet \\
\hline$N$ & Number of layers \\
\hline$P$ & Pressure, $\mathrm{kPa}$ \\
\hline $\operatorname{Pr}$ & Prandtl number \\
\hline$P_{F S}$ & Fuel vapor pressure at drop surface, $(\mathrm{Pa})$ \\
\hline$P_{M E L}$ & Self-compaction pressure of the layer, $(\mathrm{Pa})$ \\
\hline$P_{S E L}$ & Compaction pressure due to surface energy, $(\mathrm{Pa})$ \\
\hline$P_{v d W}$ & Pressure due to van der Waals bonding, $(\mathrm{Pa})$ \\
\hline$P r_{C}$ & Total compaction pressure in the layers, $(\mathrm{Pa})$ \\
\hline$P r_{p f}$ & Fluid pressure due to flow in porous layers, Eq. (16), (Pa) \\
\hline$Q_{\text {Shell,Cond }}$ & Conduction heat transfer through porous shell, (J) \\
\hline$\left|\dot{q}_{d}\right|$ & Rate of heat is spent on raising the temperature of a liquid droplet \\
\hline$R$ & Radial coordinate, Eq. (7), (m) \\
\hline$R_{L}$ & Radius of the $n^{\text {th }}$ layer, (m) \\
\hline$T$ & Radial Temperature of the droplet, Eq. (7), (K) \\
\hline$u$ & Velocity of the fluid, Eq. (16), (m/s) \\
\hline$Y_{F_{S}}$ & Mass fraction of fuel vapor at surface \\
\hline
\end{tabular}

\section{Greek Symbols:}

$\alpha$

Current interlayer distance, (m)

$\varepsilon$

Porosity of the medium, Eq. (16)

$\mu_{e}$

Equivalent viscosity, Eq. (16), ( $\left.\mathrm{N} \mathrm{s} / \mathrm{m}^{2}\right)$

$v$

Poisson's ratio

$\lambda_{f}$

Thermal conductivity in Eq. $(24,25)$

$\rho^{f}$

Density of gas, Eq. (14), $\left(\mathrm{kg} / \mathrm{m}^{3}\right)$

$\rho_{C A}$

Density of the coke, $\left(\mathrm{kg} / \mathrm{m}^{3}\right)$ 


$\begin{array}{ll}\rho_{L} & \text { Density of the liquid in the droplet, }\left(\mathrm{kg} / \mathrm{m}^{3}\right) \\ \sigma & \text { Lennard-Jones Parameter }(\mathrm{nm})\end{array}$

Subscripts:

A

$C A$

evap

$\mathrm{HFO}$

LO

$l-g$

MO

$s-g$
Asphaltene

Coke accumulated

Evaporated

Heavy fuel oil

Light oil

Between liquid and gas

Middle oil

Between solid particles and fluid

\section{References}

[1] P. Moszkowicz and L. Witzel, Modelling of very fast pyrolysis of heavy fuel oil droplets, Chem. Eng. Sci. 51 (1996), pp. 4075-4086.

[2] C. Allouis, F. Beretta, and A.D. Alessio, Structure of inorganic and carbonaceous particles emitted from heavy oil combustion, Chemosphere. 51 (2003), pp. 1091-1096.

[3] W.P. Linak, C.A. Miller, and J.O.L. Wendt, Fine particle emissions from residual fuel oil combustion: Characterization and mechanisms of formation, Proc. Combust. Inst. 28 (2000), pp. 2651-2658. 
[4] D.L. Urban and F.L. Dryer, New results on coke formation in the combustion of heavy-fuel droplets, Proc. Combust. Inst. 23 (1990), pp. 1437-1443.

[5] A. Ciajolo and R. Barbella, Pyrolysis and oxidation of heavy fuel oils and their fractions in a thermogravimetric apparatus, Fuel. 63 (1984), pp. 657-661.

[6] K.D. Bartle, J.M. Jones, A.R. Lea-Langton, M. Pourkashanian, A.B. Ross, J.S. Thillaimuthu, P.R. Waller, and A. Williams, The combustion of droplets of high-asphaltene heavy oils, Fuel. 103 (2013), pp. 835-842.

[7] N. Bomo, J. Lahaye and G. Prado, Formation of cenospheres during pyrolysis of residual fuel oils, Proc. Combust. Inst. 20 (1985), pp. 903-911.

[8] P. Antaki, Transient Processes in a rigid slurry droplet during liquid vaporization and combustion, Combust. Sci. Technol. 46 (1986), pp. 113-135.

[9] A. Lee, C.K. Law, Gasification and shell characteristics in slurry droplet burning, Combust. Flame. 85 (1991), pp. 77-93.

[10] C.R. Phillips, N.I. Haidar, and Y.C. Poon, Kinetic models for the thermal cracking of Athabasca bitumen -the effect of the sand matrix, Fuel. 64 (1985), pp. 678-691.

[11] R.O. Koseoglu, and C.R. Phillips, Kinetics of non-catalytic hydrocracking of Athabasca bitumen, Fuel. 66 (1987), pp. 741-748.

[12] D.L. Urban, S.P.C. Hueyt and F.L. Dryer, Evaluation of the coke formation potential of residual fuel oils, Proc. Combust. Inst. 24 (1992), pp. 1357-1364.

[13] S.E. Moschopedis, S. Prakash, and J.G. Speight, Thermal decomposition of asphaltenes, Fuel. 57 ( 1978), pp. 431-434. 
[14] Hayashitani, M., Bennion, D.W., Donnelly, J.K. and Moore, R.G., Thermal cracking models for Athabasca oil sands oil. Proc. of Oil Sands of Canada-Venezuela Symposium, CIM Spec. Publ. 17, 233, 1977.

[15] Hayashitani, M., Bennion, D.W., Donnelly, J.K. and Moore, R.G., Thermal cracking models for Athabasca oil sands oil. SPE 7549, $53^{\text {rd }}$ Annual Fall Technical Conference and Exhibition of the SPE, Houston, October 1-3 (1978).

[16] S.S. Sazhin, A.E. Elwardany, P.A. Krutitskii, V. Deprédurand, G. Castanet, F. Lemoine, E.M. Sazhina, and M.R. Heikal, Multi-component droplet heating and evaporation: Numerical simulation versus experimental data, Int. J. Therm. Sci. 50 (2011), pp. 11641180

[17] S.S. Sazhin, M. Al Qubeissi, R. Kolodnytska, A.E. Elwardany, R. Nasiri, and M.R. Heikal, Modelling of biodiesel fuel droplet heating and evaporation, Fuel. 115 (2014), pp. 559572.

[18] S.S. Sazhin, P.A. Krutitskii, I.G. Gusev, and M.R. Heikal, Transient heating of an evaporating droplet, Int. J. Heat Mass Tran. 53 (2010), pp. 2826-2836.

[19] J.S. Chin and A.H. Lefebvre, Steady-State Evaporation Characteristics of Hydrocarbon Fuel Drops. AIAA Journal. 21(1983), pp 1437-1443.

[20] S. Sazhin, Droplets and Sprays, Springer-Verlag, London, 2014.

[21] S. Ergun, Fluid flow through packed column, Chem. Eng. Prog. 48 (1952), pp. 89-94.

[22] O.C. Zienkiewicz, R.L. Taylor, P. Nithiarasu, The Finite Element Method for Fluid Dynamics (Seventh Edition). 2014; pp 312. 
[23] M. Todt, R.D. Bitsche, M.A. Hartmann, F.D. Fischer, F.G. Rammerstorfer, Growth limit of carbon onions - A continuum mechanical study, Int. J. Solids and Struct. 51 (2014), pp. $706-715$.

[24] M. Todt, F.G. Rammerstorfer, F.D. Fischer, P.H. Mayrhofer, D. Holec, and M.A. Hartmann, Continuum modeling of van der Waals interactions between carbon onion layers, Carbon. 49 (2011), pp. $1620-1627$.

[25] T.K. Kayal and M. Chakravarty, Modeling of trickle flow liquid fuel combustion in inert porous medium, Int. J. Heat Mass Tran. 49 (2006), pp. 975-983.

[26] P.-X. Jiang and X.-C. Lu, Numerical simulation of fluid flow and convection heat transfer in sintered porous plate channels, Int. J. Heat Mass Tran. 49 (2006), pp. 1685-1695. 


\section{List of Figures}

Figure 1 The P2 model of the asphaltene cracking mechanism of Phillips et al. [10]

Figure 2 The stages of droplet evaporation, shell formation and final cenosphere formation

Figure 3 (a) Radial temperature distribution in the droplet; (b) Variation of reaction rate constants

Figure 4 Pressure balance for $P r_{p f}$ and $P r_{C}$

Figure 5 (a) Variation in outer diameter $\left(D_{\text {SOut }}\right)$, inner diameter $\left(D_{S I n}\right)$ of the shell, droplet diameter $\left(D_{I n}\right)$ and (b) Variation in the thickness (h) of the shell in relation to differen droplet diameters

Figure 6 Variations in (a) fuel evaporation and (b) gas formation for different droplet diameters

Figure 7 Variations in (a) coke formation and (b) coke accumulation for different droplet diameters

Figure 8 Variation of velocity of evaporated fuel $(\mathrm{m} / \mathrm{s})$ for different droplet diameters

Figure 9 (a) Variation of shell dimension of EPRI 4011 of Urban et al., [4, 12] and (b) Comparison of present model with experimental results of Urban et al., [4, 12] 


\section{List of Tables}

Table 1 Fuel properties used in the numerical model and Urban et al. [12]

Table 2 Kinetic parameters of the P2 asphaltene cracking model of Phillips et al. [10] 


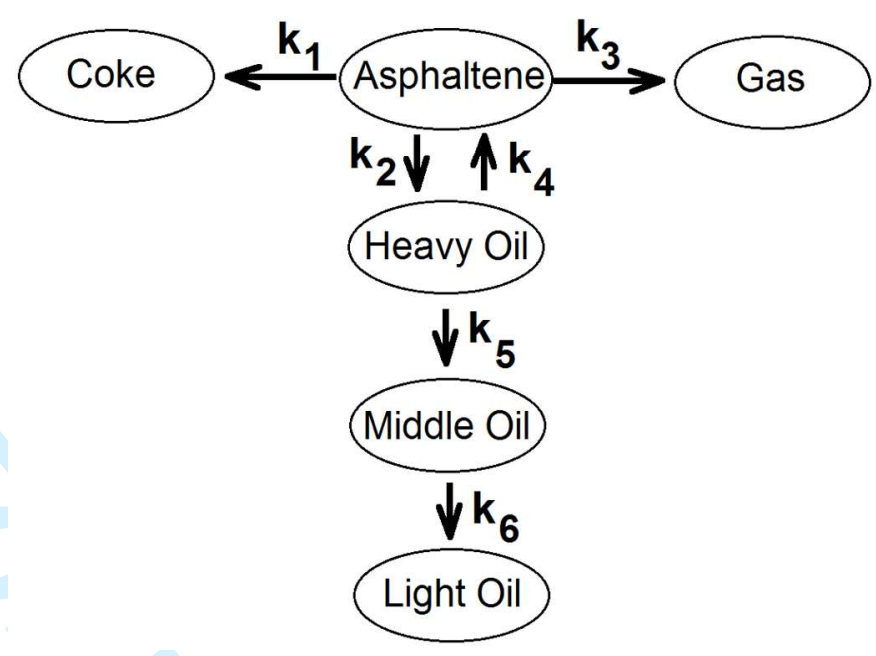

Figure 1 The P2 model of the asphaltene cracking mechanism of Phillips et al. [10] 


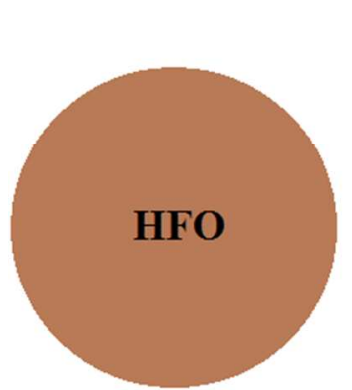

(a)

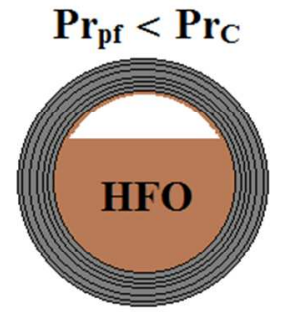

(d)

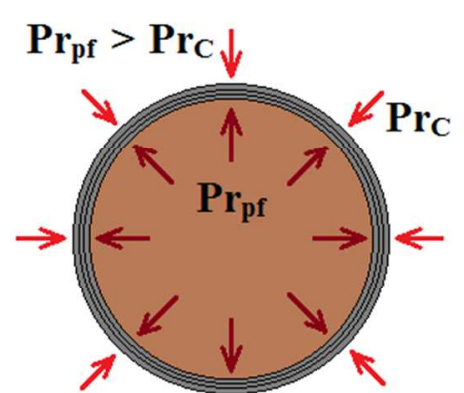

$\uparrow(b)$

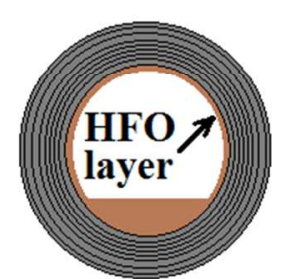

(e)
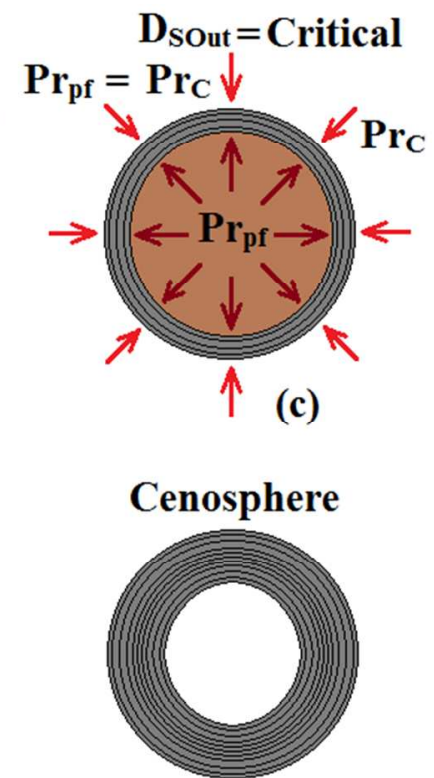

(f)

Figure 2 The stages of droplet evaporation, shell formation and final cenosphere formation 

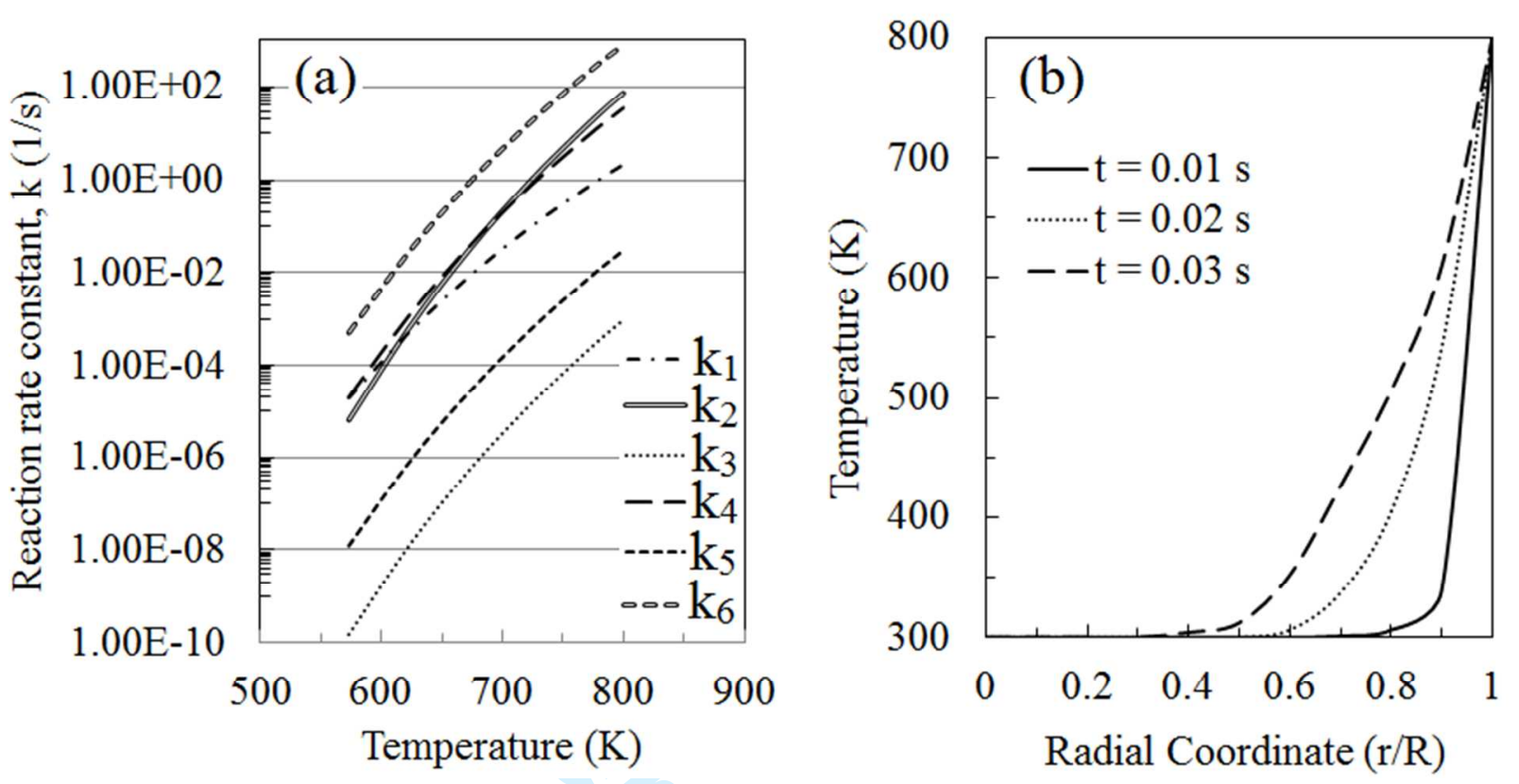

Figure 3 (a) Radial temperature distribution in the droplet; (b) Variation of reaction rate constants 


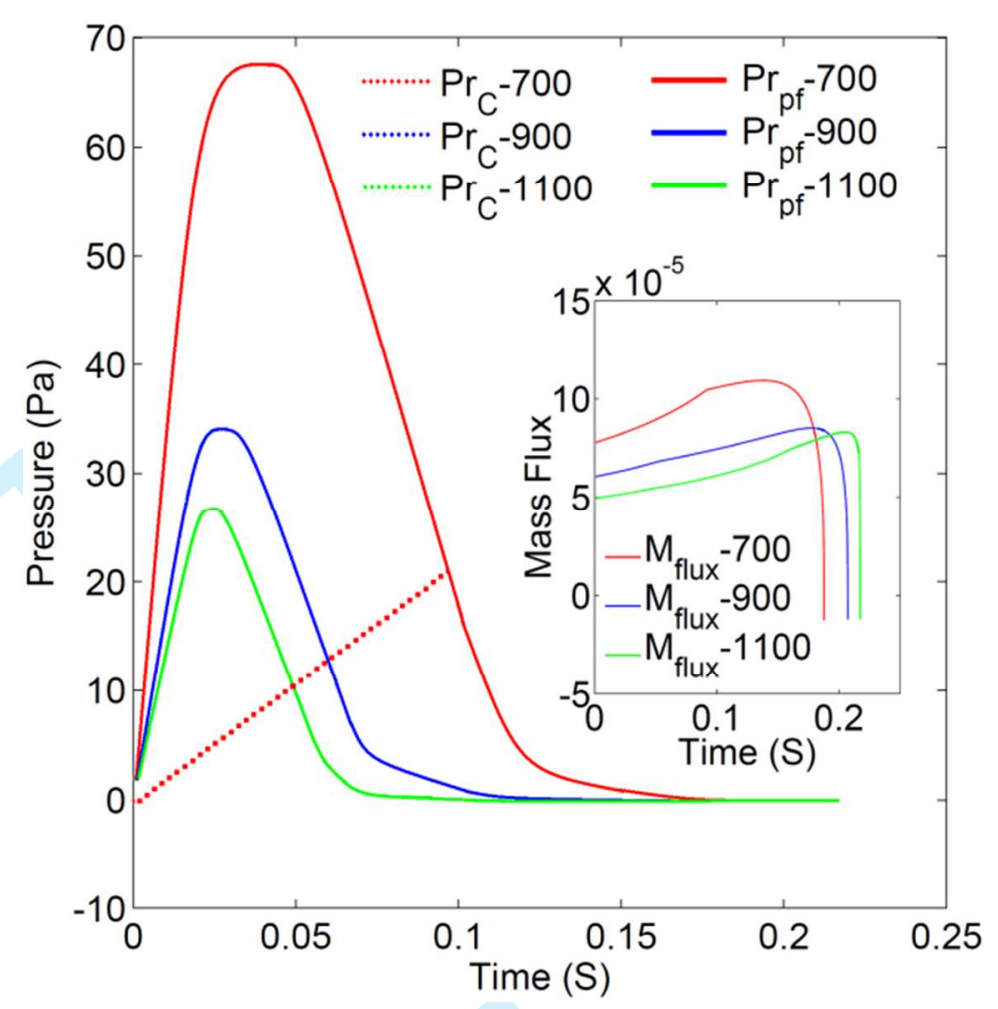

Figure 4 Pressure balance for $P r_{p f}$ and $P r_{C}$ 

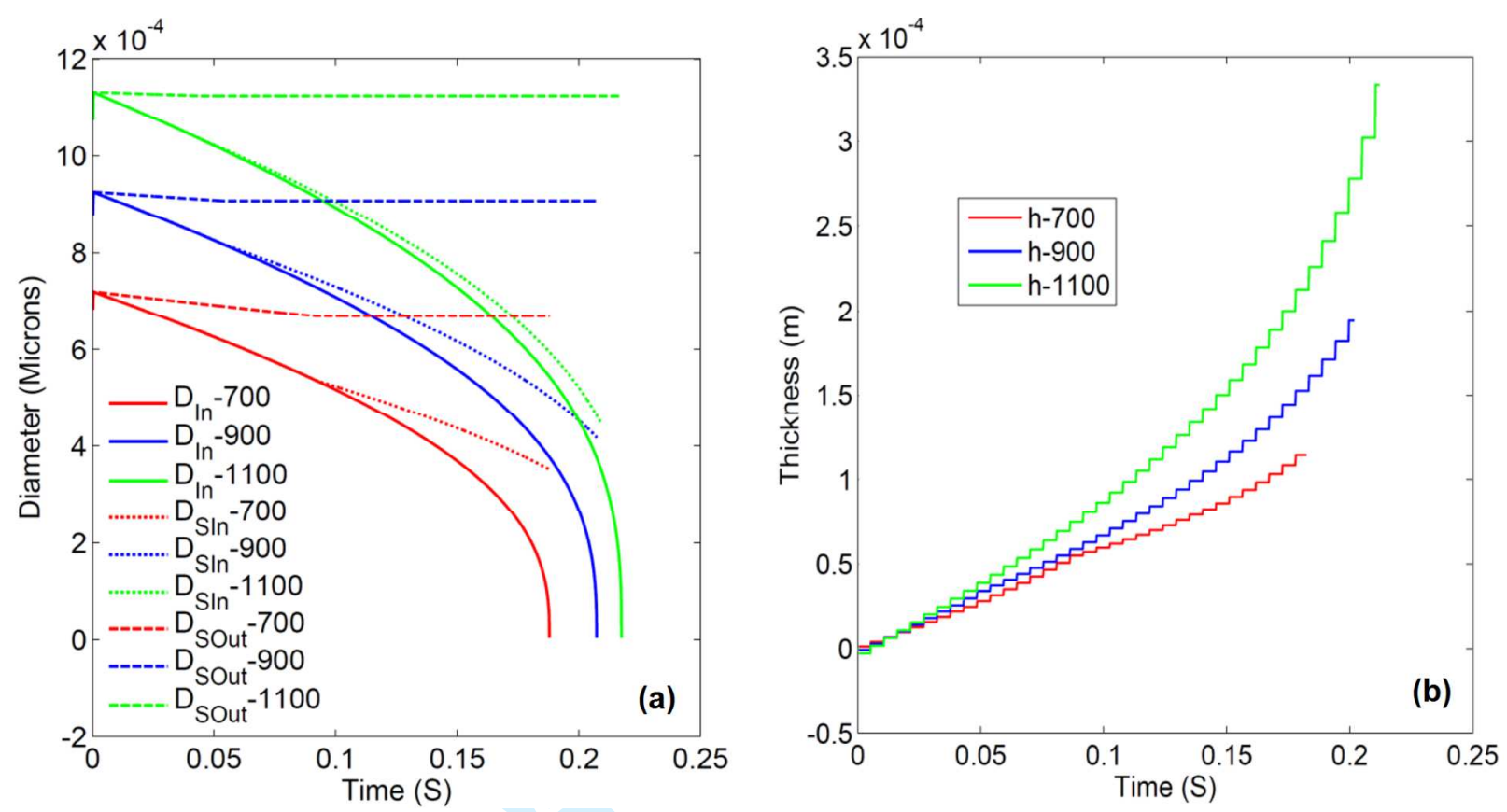

Figure 5 (a) Variation in outer diameter $\left(D_{\text {SOut }}\right)$, inner diameter $\left(D_{\text {SIn }}\right)$ of the shell, droplet diameter $\left(D_{I n}\right)$ and (b) Variation in the thickness (h) of the shell in relation to differen droplet diameters 

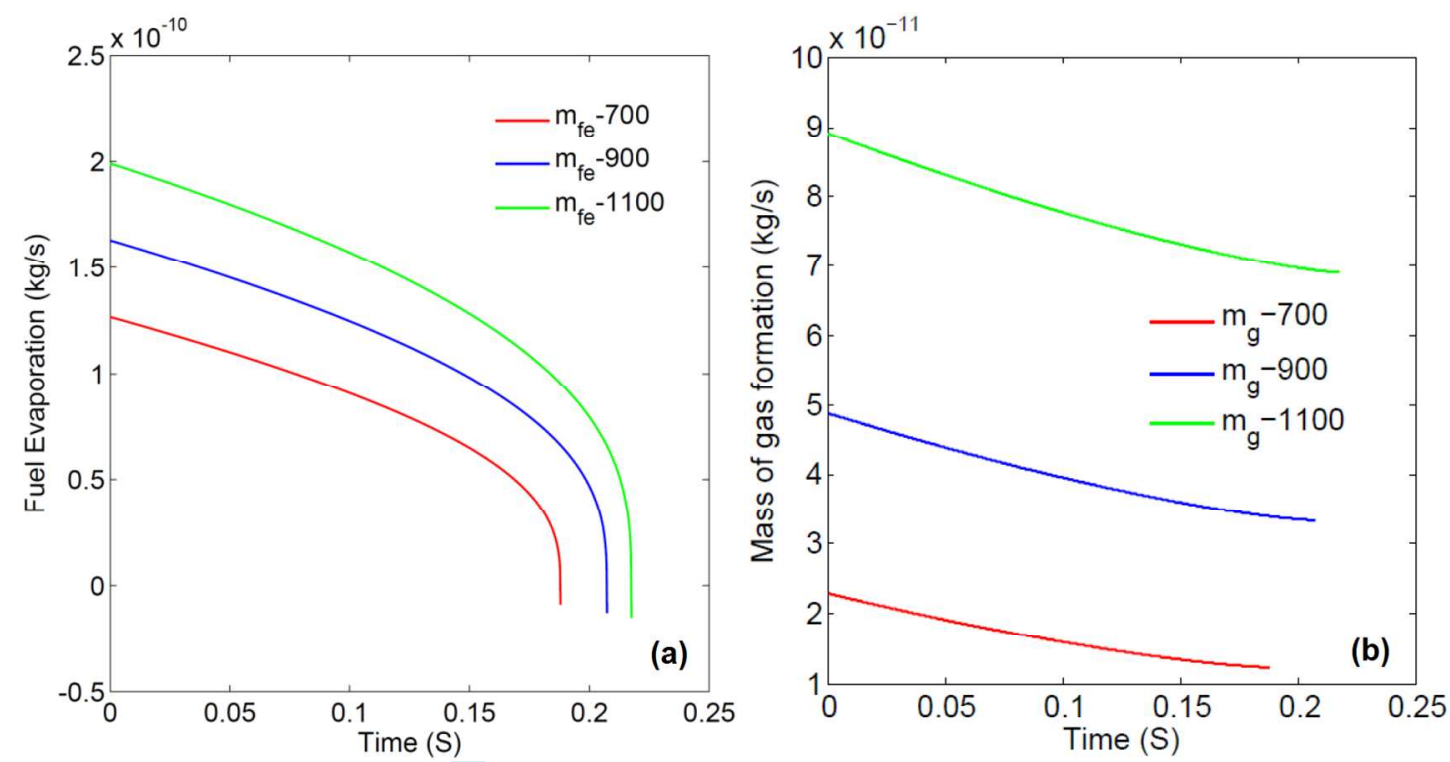

Figure 6 Variations in (a) fuel evaporation and (b) gas formation for different droplet diameters 

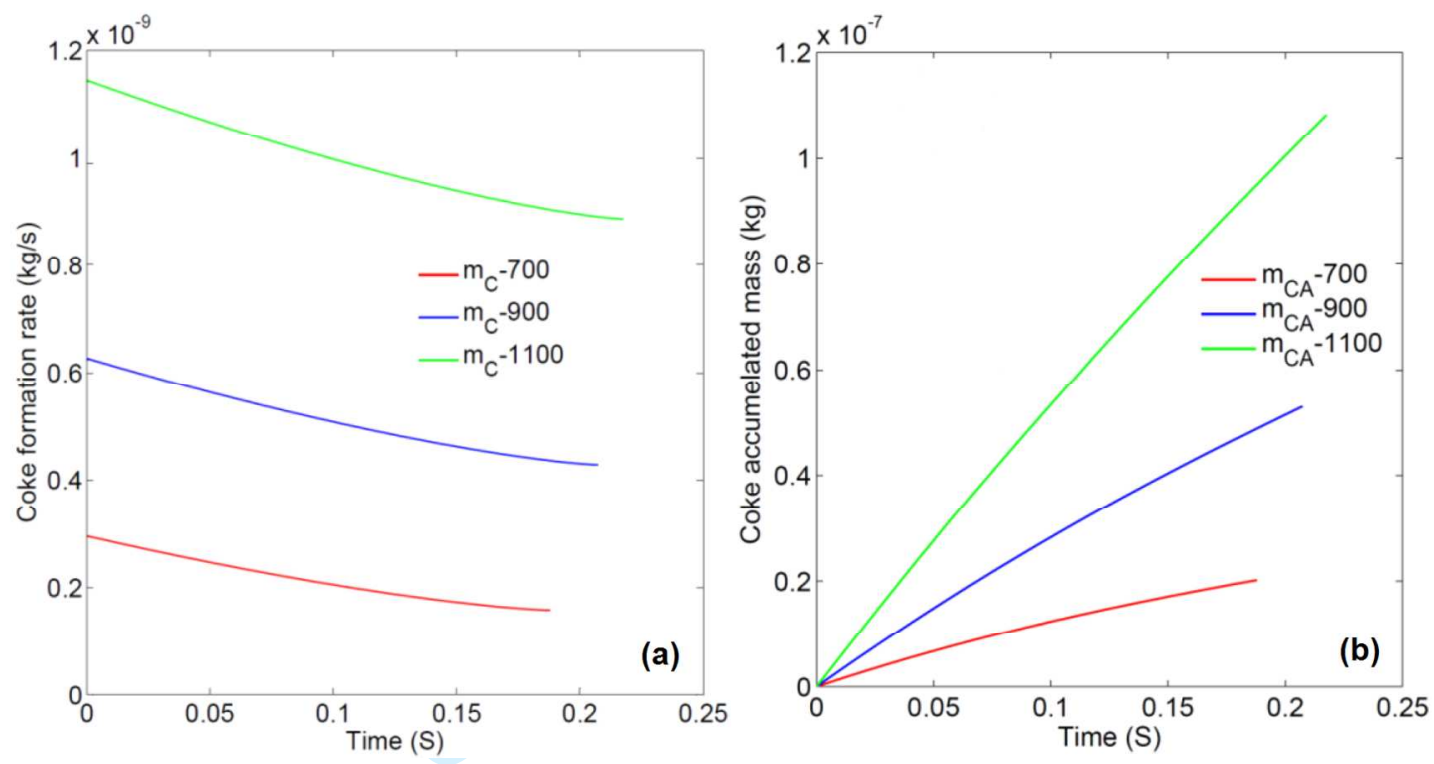

Figure 7 Variations in (a) coke formation and (b) coke accumulation for different droplet diameters 


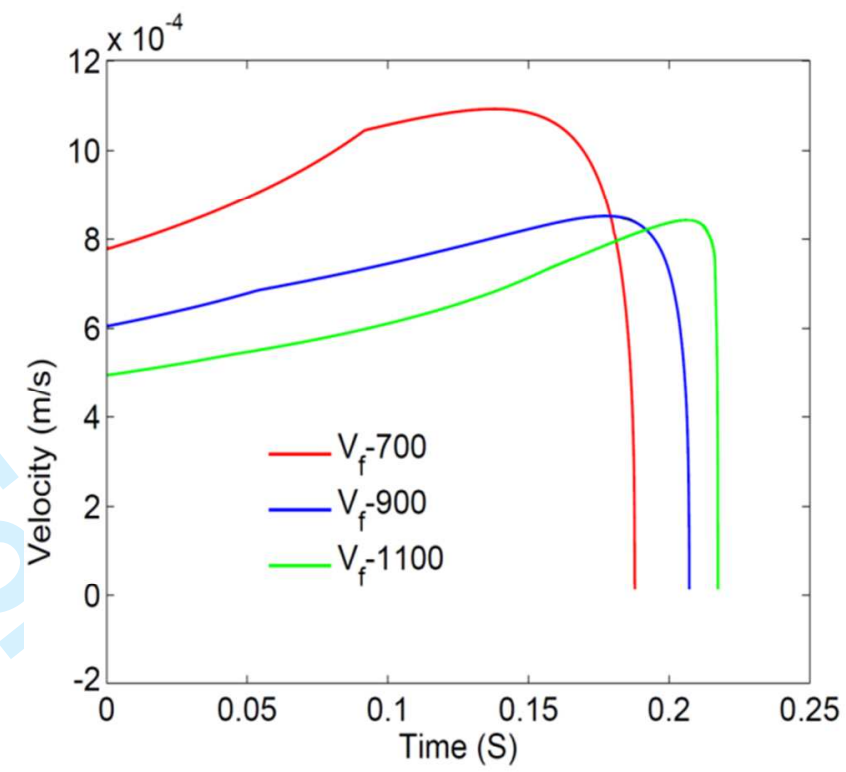

Figure 8 Variation of velocity of evaporated fuel $(\mathrm{m} / \mathrm{s})$ for different droplet diameters 

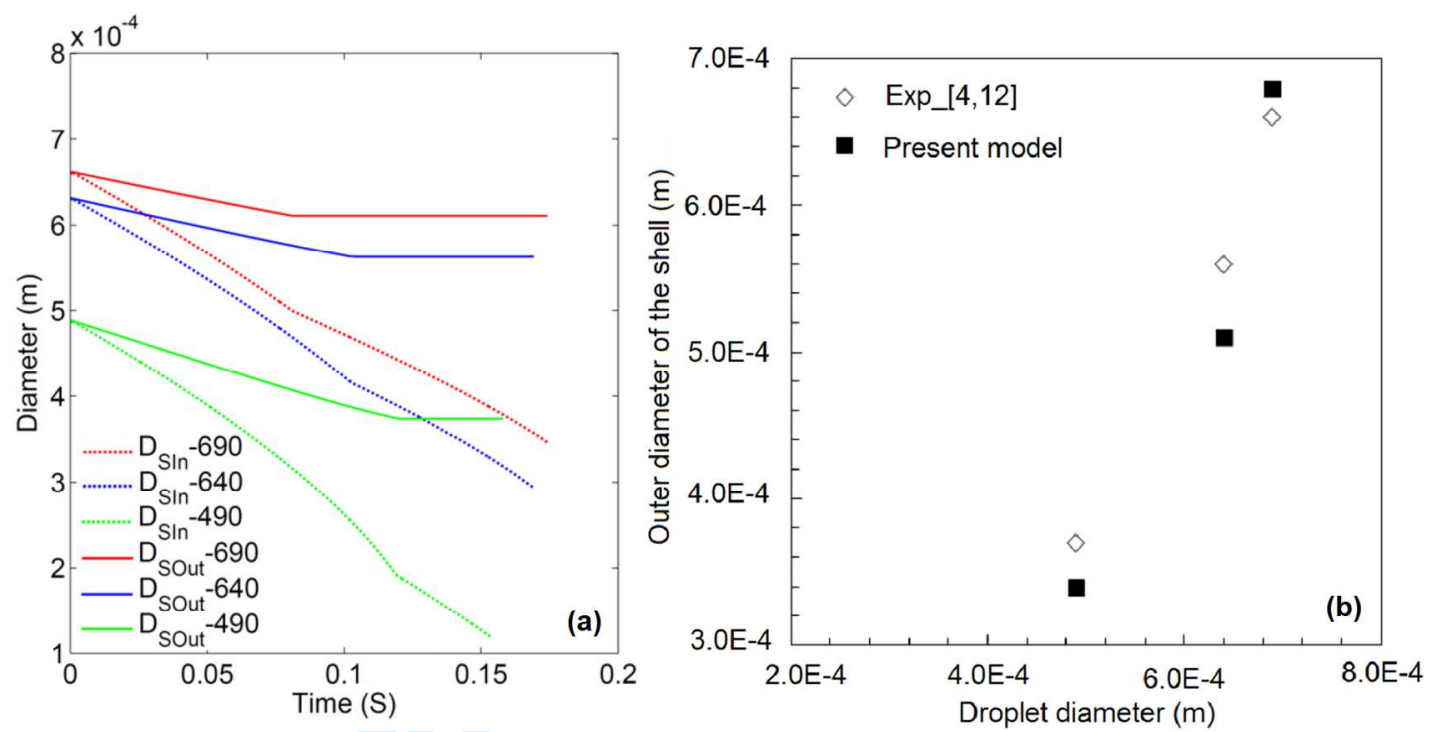

Figure 9 (a) Variation of shell dimension of EPRI 4011 of Urban et al., [4, 12] and (b) Comparison of present model with experimental results of Urban et al., [4, 12] 
Table 1 Fuel properties used in the numerical model and Urban et al. [12]

\begin{tabular}{|c|c|c|}
\hline Property & Present fuel & EPRI $4011[12]$ \\
\hline Density at $288 \mathrm{~K}\left(\mathrm{~kg} / \mathrm{m}^{3}\right)$ & 990 & 970 \\
\hline Specific gravity (oAPI) & 12.9 & \\
\hline Surface Tension at $293 \mathrm{~K}(\mathrm{~N} / \mathrm{m})$ & 0.0284 & \\
\hline Pour point $\left({ }^{\circ} \mathrm{C}\right)$ & $9-12$ & \\
\hline Flash pint $\left({ }^{\circ} \mathrm{C}\right)$ & $60-99$ & \\
\hline Kinematic viscosity at $40^{\circ} \mathrm{C}(\mathrm{cSt})$ & 617.7 & \\
\hline Boiling point $\left({ }^{\circ} \mathrm{C}\right)$ & 550 & \\
\hline Carbon (\%mass) & 84.0 to 87.0 & 85.7 \\
\hline Hydrogen (\%mass) & 10.3 to 11.5 & 10.1 \\
\hline Sulfur (\%mass) & 2.35 to $3.8 \%$ & 2.31 \\
\hline Oxygen (\%mass) & 0.037 to 0.053 & \\
\hline Nitrogen (\%mass) & 0.023 to 0.04 & 0.43 \\
\hline Ash (\%mass) & 0.03 to 0.053 & 0.07 \\
\hline CCR (\%wt) & 16.0 & \\
\hline Max. Asphaltene content (\%wt) & 16.0 & 10.35 \\
\hline Nickel (ppm) & 42 & 297 \\
\hline Vanadium (ppm) & 130 & \\
\hline$(\mathrm{HHV})(\mathrm{MJ} / \mathrm{kg})$ & 43.6 & \\
\hline$(\mathrm{LHV})(\mathrm{MJ} / \mathrm{kg})$ & 41 to 42.5 & \\
\hline
\end{tabular}


Table 2 Kinetic parameters of the P2 asphaltene cracking model of Phillips et al. [10]

\begin{tabular}{|c|c|c|}
\hline & Activation energy $\left(\mathrm{E}_{\mathrm{a}}\right)(\mathrm{kJ} / \mathrm{mol})$ & Frequency factor $(\mathrm{A})\left(\mathrm{s}^{-1}\right)$ \\
\hline $\mathrm{k}_{1}$ & 195 & $1.16 \times 10^{13}$ \\
\hline $\mathrm{k}_{2}$ & 273 & $4.99 \times 10^{19}$ \\
\hline $\mathrm{k}_{3}$ & 263 & $1.41 \times 10^{14}$ \\
\hline $\mathrm{k}_{4}$ & 241 & $1.91 \times 10^{17}$ \\
\hline $\mathrm{k}_{5}$ & 247 & $4.04 \times 10^{14}$ \\
\hline $\mathrm{k}_{6}$ & 240 & $3.79 \times 10^{18}$ \\
\hline
\end{tabular}




\section{Reviewer: 1}

The topic of the paper is relevant to the journal and the paper contains some new results. However, it requires extensive revision before I am able to recommend it for publication in Combustion Theory and Modelling. My main general concern is that the model described in the paper is based on several previously developed models. The authors should not assume that the readers of the paper are familiar with these models. The main ideas of the previous models should be described in more detail to make the whole paper more reader friendly.

Response: Assumptions and highlights of results of Antaki, Lee and law, and Moszkowicz et al. models are elaborated in the revised manuscript.

These are some specific issues which concern me.

1. Eq. (8) is correct only in the limiting case when $B M=B T$ (see Sazhin, Droplets and Sprays, Springer, 2014, for further details). This needs to be explicitly mentioned if the authors intend to base their analysis on this equation.

Response: Eq. (8) modified, assumptions and conditions are mentioned in the revised manuscript.

2. Eq. (7), which the authors use, is not explained. It is not clear how the authors used it. What sort of boundary conditions did they use?

Response: Boundary conditions for the Eq. (7) are added in the revised manuscript:

3. Eq. (21) is not clear. How can heat be transferred from gas to liquid bypassing the surface? How was the conduction heat flux calculated?

Response: Here in Eq. (23), the heat transfer takes place between liquid and gas in the porous shell. The liquid, at its boiling point, spreads into the porous shell. Since evaporation takes place within this zone, regions are filled with liquid and gas. Conduction is considered in the phase three (flow through rigid shell) and it is included in Eq. (23) as $Q_{\text {Shell,Cond }}$. Here, the $Q_{\text {Shell,Cond }}$ is a function of the shell thickness only because the outer (environment) gas temperature $\left(\mathrm{T}_{\mathrm{g}}\right)$ and the liquid fuel in the droplet is at boiling temperature, hence the temperature gradient $(\Delta \mathrm{T})$ is fixed. The porosity of the shell is considered during the calculation of shell surface area.

4. In the conclusions, the assumptions of the model tend to be presented as the results of the paper. Most of sub-section 5 of the conclusions should be removed from the paper. The conclusions as a whole look far too long for the results they intend to summarize.

Response: The conclusions section has been rewritten, removing most of sub-section 5, and shortening.

5. The paper requires extensive editing and numerous typos need to be corrected.

Response: The manuscript has been edited and typo errors corrected. 


\section{Reviewer: 2}

This is an interesting paper and ultimately should be published, but it is not easy to follow. Authors must provide a Nomenclature. Authors should also pay attention to units, in their nomenclature table. Editor should make this mandatory.

Response: A Nomenclature section has been added in the revised manuscript.

1. I am not sure if Eq. 7 contributes much without the boundary and initial conditions being stated (mathematically).

Response: The boundary conditions for the Eq. (7) have been added in the revised manuscript.

2. It would also help if the authors would briefly summarize the salient features of the literature models they use. For example, does the Spalding evaporation model (p8) properly account for latent heat effects? The Todt Model (Eqn 18 and 19) for char formation has certain physical assumptions in it. It would help if these were summarized, so that the reader could figure out whether the model was correctly applied.

Response: Assumptions and highlights of results of the Antaki, Lee and Law, and Moszkowicz et al. models are elaborated in the revised manuscript. Eq. (8) has been modified and required conditions are added. The concept of, and equations for, Van der Waals attraction between layers, self-compaction and surface tension energy of the layers are considered from the Todt et al. model. Char formation characteristics and the corresponding assumptions have not been analyzed by Todt et al.

3. I could not easily find typical values for the porosity of the shell. Is it constant or does it vary with time?

Response: The porosity of the shell is considered constant. It is assumed that the coke particles are angular grains with a porosity of $39 \%$.

Overall this is an interesting piece of work, but the presentation could be improved. I think the work could be presented in a clearer fashion, and I would encourage the authors to do so.

Response: All the typo errors are corrected. Manuscript is modified with all improvements suggested by reviewers. 